\title{
Review
}

\section{Impacts of local human activities on the Antarctic environment}

\author{
T. TIN ${ }^{1 *}$, Z.L. FLEMING ${ }^{2}$, K.A. HUGHES 3 , D.G. AINLEY4, P. CONVEY3, C.A. MORENO 5 , S. PFEIFFER ${ }^{6,9}$, \\ J. SCOTT ${ }^{7}$ and I. SNAPE ${ }^{8}$
}

\author{
${ }^{1}$ Antarctic Southern Ocean Coalition (ASOC), BP 80358, 45163 Olivet, CEDEX 3, France \\ ${ }^{2}$ Department of Chemistry, University of Leicester, University Road, Leicester LE1 7RH, UK \\ ${ }^{3}$ British Antarctic Survey, NERC, High Cross, Madingley Road, Cambridge CB3 OET, UK \\ ${ }^{4}$ H.T. Harvey and Associates, 983 University Avenue, Bldg D, Los Gatos, CA 95032, USA \\ ${ }^{5}$ Instituto de Ecología y Evolución, Universidad Austral de Chile, Casilla 567, Valdivia, Chile \\ ${ }^{6}$ University of Jena, Dornburger Str. 159, D-07743 Jena, Germany \\ ${ }^{7}$ School of Geography and Environmental Studies, University of Tasmania, Private Bag 78, Hobart, TAS 7001, Australia \\ ${ }^{8}$ Australian Antarctic Division, Channel Highway, Kingston, TAS 7050, Australia \\ ${ }^{9}$ current address: University of Potsdam, Maulbeerallee 1, D-14469 Potsdam, Germany \\ *tinatink@gmail.com
}

\begin{abstract}
We review the scientific literature, especially from the past decade, on the impacts of human activities on the Antarctic environment. A range of impacts has been identified at a variety of spatial and temporal scales. Chemical contamination and sewage disposal on the continent have been found to be long-lived. Contemporary sewage management practices at many coastal stations are insufficient to prevent local contamination but no introduction of non-indigenous organisms through this route has yet been demonstrated. Human activities, particularly construction and transport, have led to disturbances of flora and fauna. A small number of non-indigenous plant and animal species has become established, mostly on the northern Antarctic Peninsula and southern archipelagos of the Scotia Arc. There is little indication of recovery of overexploited fish stocks, and ramifications of fishing activity on bycatch species and the ecosystem could also be far-reaching. The Antarctic Treaty System and its instruments, in particular the Convention for the Conservation of Antarctic Marine Living Resources and the Environmental Protocol, provide a framework within which management of human activities take place. In the face of the continuing expansion of human activities in Antarctica, a more effective implementation of a wide range of measures is essential, in order to ensure comprehensive protection of the Antarctic environment, including its intrinsic, wilderness and scientific values which remains a fundamental principle of the Antarctic Treaty System. These measures include effective environmental impact assessments, long-term monitoring, mitigation measures for non-indigenous species, ecosystem-based management of living resources, and increased regulation of National Antarctic Programmes and tourism activities.
\end{abstract}

Received 31 July 2008, accepted 10 November 2008

Key words: Antarctic Treaty System, contamination, ecosystem based management, human impacts, non-indigenous species, tourism

\section{Introduction}

Impacts of human activities on the Antarctic environment date back to the 18th century with the arrival of the first exploring and sealing expeditions. Harvesting of seals, whales and penguins led to local extinctions as well as the overall near-extinction of a number of species. The end of the 19th and the early 20th centuries, the so-called "Heroic Age" of exploration, brought construction of the first stations in Antarctica, which together with the development of whaling started a new era of sustained human presence, as well as a legacy of environmental pollution (Blanchette et al. 2004). This process was accelerated by the international scientific efforts fostered under the International Geophysical Year of 1957/58, and, since then, the intensity and scale of human activities in Antarctica have continued to increase. Users have encompassed not only explorers, but also scientific researchers, station support personnel, fishers, whalers and more recently, commercial and private tourists. More recently, the International Polar Year 2007-2009 has catalysed further scientific and public interest in the 'white continent', and inevitably given further impetus to human activity in and around the continent. Regardless of the nature of the activity, survival in Antarctica necessitates the use of fossil fuels and imported construction materials, the production of wastes, and interactions with landscapes, flora and fauna.

International regulation of the impacts of human activities in Antarctica began in 1948 with the entry into force of the International Convention for the Regulation of Whaling (signed in 1946) and the establishment of the International 
Whaling Commission (IWC). In 1961, the Antarctic Treaty (signed in 1959) entered into force. It stipulated the prohibition of military activities and nuclear testing in the area south of $60^{\circ} \mathrm{S}$ and required Treaty Parties to take measures regarding the preservation and conservation of living resources in Antarctica. Over the next 50 years, the Antarctic Treaty System (ATS) has expanded to include the Antarctic Treaty and three other legal instruments. The first addition to the ATS was the Agreed Measures on the Conservation of Flora and Fauna (signed in 1964, entered into force 1982), which provides protection for native mammals and birds. Many of its measures have since been subsumed or developed in the Annexes to the Environmental Protocol (see below). The Convention for the Conservation of Antarctic Seals (signed in 1972, entered into force in 1978) sets harvesting limits for seals should sealing recommence and sets aside several seal reserves. Management of fisheries was initiated when the Convention for the Conservation of Antarctic Marine Living Resources (CCAMLR) (signed in 1980) came into force in 1982. The Protocol on Environmental Protection to the Antarctic Treaty (signed in 1991, and more commonly referred to as the Environmental Protocol or Madrid Protocol) came into force in 1998. It prohibits mineral resource activities and amongst other things stipulates, that:

"The protection of the Antarctic environment and dependent and associated ecosystems and the intrinsic value of Antarctica, including its wilderness and aesthetic values and its value as an area for the conduct of scientific research, in particular research essential to understanding the global environment, shall be fundamental considerations in the planning and conduct of all activities in the Antarctic Treaty area."

Over the past decade, the intensity and diversity of human activities have continued to increase. According to the Council of Managers of Antarctic Programs (COMNAP), 53 active research stations now exist in Antarctica, with a peak capacity of approximately 4000 people in summer and 1000 in winter. New stations and transport logistics continue to be developed, shortening the travel time that it takes to access the Antarctic continent (Frenot et al. 2005) and allowing research to take place further into the remote polar plateau. For nearly 40 years, only two stations existed on the polar plateau: the United State's Amundsen-Scott Base at South Pole and Russia's Vostok Station at the continent's "Pole of Inaccessibility". Since 1995, three new stations have been built on the plateau, with another currently being planned. Increased numbers of intercontinental cruises and flights have made it faster and cheaper to bring more people to Antarctica. In the last 10 years, the numbers of tourists visiting and landing in the Antarctic region has increased by over three-fold
(IAATO 2008). Tourism brought 60000 passengers, crew and staff to Antarctica during summer 2006-2007, with one ship alone carrying over 3000 passengers (IAATO 2007). Fishing activities, initiated in the 1960s, have continued in the South Atlantic and Indian Ocean sectors of the Southern Ocean, and have also expanded southward towards the continent, including the hitherto unexploited Ross Sea. Shipping incidents that took place during 2007 alone - the sinking of the MS Nordkapp and MS Explorer, collision of the MS Fram with a glacier, rescue of a disabled fishing vessel as well as a fire onboard the Nisshin Maru - bring into sharp focus the expansion of environmental and safety risks.

In view of the probable continuing expansion in intensity and diversity of human activities in Antarctica, it is timely to provide a review of the state of knowledge of human impacts and their management in the Antarctic and the Southern Ocean. The purpose of this review is to 1) provide a wideranging assessment of recent scientific studies relating to the existence and implications of human impacts on the southern polar environment, 2) examine how the information provided by human impacts research can be fed back into the current environmental management regimes (primarily the Environmental Protocol and CCAMLR) in order to inform decisions, and 3) discuss what is needed to improve the management and minimization of environmental impacts and to strengthen the protection of the Antarctic environment in face of changing demands in the 21 st century. Such a compilation and assessment of information can provide an objective baseline against which improvements can be measured, and will inform ongoing debates, both in public fora and within the ATS, on the future direction, mechanisms and implementation of environmental management as well as enhancing the importance of stewardship in Antarctica.

In the 1990s, around the time of the negotiation of the Environmental Protocol, a large amount of research on the impacts of human activities in Antarctica was produced. Much of this research has been reviewed in textbooks, including Hansom \& Gordon (1998), Bargagli (2005) and Knox (2006). Research coverage focussed on environmental pollution, disturbance to flora and fauna, and fishery-related impacts on marine ecosystems. Since then, research on human impacts has been expanded and diversified by researchers from many different countries. In the present study, we aim to pick up where these earlier reviews have left off and assess recent research and evidence on the impacts of human activities in Antarctica over the past decade (1998-2008). We intentionally focus mainly on studies published since 1998, and on the area south of $60^{\circ} \mathrm{S}$ where the Antarctic Treaty applies; this is the period covered, too, in the recent analysis of Halpern et al. (2008), which summarized human impacts on the world's oceans. However, we also draw on examples from the sub-/peri-Antarctic islands and the area covered by 
CCAMLR that extends north of $60^{\circ} \mathrm{S}$ up to the Antarctic Polar Front, as they often provide relevant information, given the similarities in native biota, the progression along environmental gradients from sub- to maritime Antarctic conditions and trends in human activity. Maintaining and operating stations and their associated logistics and scientific activities, tourism and fisheries are the main activities that currently take place in Antarctica. Their impacts - chemical and sewage contamination, disturbance of terrestrial and marine ecosystems and alteration of foodwebs - are considered here. Our main source of information comes from studies published in peer-reviewed journals. However, in the cases where few published studies are available, and especially in the discussion of the Antarctic environmental management regimes, we also make use of documents from the ATS secretariat and CCAMLR to provide supplementary information. While care has been taken to be as comprehensive as possible in the review, it must be noted that not all activities or studies undertaken in Antarctica are reflected in the accessible literature. We also recognize that other fundamentally important impacts also arise from human activities that originate beyond Antarctica itself, in particular relating to global climate change, ozone depletion, and long-range pollution, but these lie beyond the scope of this paper, and we refer the reader to wider authoritative recent reviews in this context (e.g. Bargagli 2005, Turner et al. 2005, Bergstrom et al. 2006).

\section{Chemicals}

Chemical contamination, especially through fuel spills and exhaust gases, is the most widespread environmental impact of human activities in Antarctica (Bargagli 2005). Contamination from land-based operations typically extends for hundreds of metres rather than kilometres (e.g. Kennicutt 2003, Stark et al. 2003b, 2005) although the marine fuel spill associated with the Bahia Paraiso - the largest spill to date in Antarctica - was much more extensive, affecting an area of about $3 \mathrm{~km}$ radius (Kennicutt et al. 1991). For contamination emanating from terrestrial sources, flux is highly variable within and between seasons (Sheppard et al. 2000, Snape et al. 2002). For example, the abandoned waste site at Wilkes Station in East Antarctica sometimes melts very little, and there is almost no spread of contamination. In contrast, in years of extensive melting, a plume of fuel has been observed to extend out into Newcomb Bay for several kilometres (S. Potter, Australian Antarctic Division, personal communication 2008). Several chemical and biological studies from a range of terrestrial and nearshore marine habitats all indicate that contaminants and their associated impacts are long-lived in the Antarctic environment. Some contaminated sites, such as the well-studied Winter Quarters Bay which served as a dumpsite for McMurdo
Station on Ross Island until the mid-1980s, are as contaminated as the most contaminated marine environments anywhere. The sorts of impacts adjacent to stations are similar in many ways to those seen in temperate regions, but are all the more significant because they have impacted relatively rare habitat types, natural attenuation rates are very slow, and mounting evidence also indicates that individuals and communities are more sensitive to contamination in cold regions (e.g. King \& Riddle 2001, Schafer et al. 2007).

Before 1998, scientific research on locally derived contaminants in the Antarctic focussed on four commonly adopted aspects of assessment involving definition of the nature of the contamination, its distribution, environmental impact, and an estimation of its longevity (e.g. Kennicutt et al. 1991, Green et al. 1992, Lenihan et al. 1995, McDonald \& Murrell 1997). Research undertaken since 1998 has continued on these four aspects, but has become more process-oriented. Chemical fingerprinting, elucidation of biogeochemical processes and pathways, ecological risk assessment methods and remediation research are among some of the areas where significant advances have been made.

\section{Sources of contamination}

Recent studies have further defined the nature of local chemical contamination in Antarctica and the main sources or types of chemical contamination are now well established: fuel spills, heavy metals/metalloids (typically copper, lead, zinc, cadmium, mercury, arsenic) and polychlorinated biphenyl (PCB) contamination derived from abandoned waste disposal sites, chemicals disposed of through the sewage system including metals and polybrominated diphenyl ether (PBDE) flame retardants, as well as the release of other persistent contaminants, such as polycyclic aromatic hydrocarbons (PAH) and polychlorinated dibenzodioxins (PCDDs), from combustion processes (e.g. Snape et al. 2001b, Santos et al. 2005, Negri et al. 2006, Hale et al. 2008). A significant amount of persistent atmospheric contaminants is also transported to Antarctica from other continents, especially in the Southern Hemisphere. The import of trace gases such as carbon dioxide (from the burning of biomass and fossil fuels) and chlorofluorocarbons (CFCs, used as flame-retardants and refrigerants) has significantly changed the Antarctic atmosphere in recent decades. Through sea ice, persistent atmospheric contaminants are also transferred to water and organisms and can accumulate in tissues and biomagnify in food chains. For example, dichlorodiphenyldichloroethylene (DDE), a derivative of dichlorodiphenyltrichloroethane (DDT), a pesticide that was used globally, has been found to be widespread in Antarctic organisms (Bargagli 2005) despite restrictions on its use under the Stockholm Convention on Persistent Organic Pollutants. 


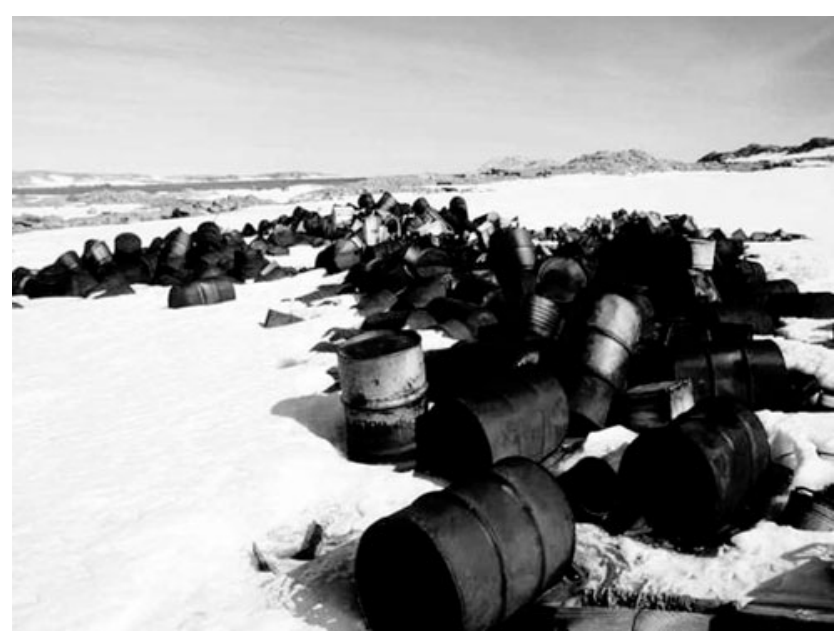

Fig. 1. Waste disposal site at the abandoned Wilkes Station. (Photo by Ian Snape)

Chemical contamination from abandoned waste disposal sites and past fuel spills are a legacy from when environmental management was less stringent prior to the entry into force of the Environmental Protocol in 1998 (Fig. 1). There is no comprehensive inventory of contamination in Antarctica, although the amount of contaminated soil and waste has been estimated to be of the order 1-10 million $\mathrm{m}^{3}$ (Snape et al. 2001b). In global terms, this is a very small volume of contaminated material, and Antarctica's overall contamination legacy is not a large footprint in absolute terms. To put the amount of contamination into context, however, requires consideration of the proportion of habitat that is affected and the geographic scale of assessment. Only about $0.34 \%$ of the Antarctic continental area is ice-free (BAS 2004), mostly in the Peninsula and remote mountain regions. The total surface area of rocky outcrops within $5 \mathrm{~km}$ of the coast has been estimated to be around $5970 \mathrm{~km}^{2}$ (D. Smith, Australian Antarctic Data Centre, personal communication 2008). This area encompasses all Antarctic terrestrial maritime land with rock and soil, and, combined with the shallow nearshore areas, is a very rare and unique type of habitat on a continent that is mostly ice-covered. It is often these isolated Antarctic oases where most wildlife congregates, and coincidentally this is also where most of the research stations are located and where tourists visit. Viewed this way, it becomes practicable to visualize an area about six times the size of King George Island, representing the total coastal Antarctic polar habitat with rock/soil and shallow water, being occupied by 53 active research stations as well as a number of disused stations and infrastructure, many with one or more abandoned waste disposal areas and/or fuel contaminated soil, and a contaminated footprint in the adjacent marine ecosystem. Whilst in some cases it appears that the footprint can extend for up to several hundred metres offshore, the marine effect has yet to be investigated for most coastal stations with the extent of outward ripple effects unknown. Thus, Antarctic chemical contamination may be limited in its absolute areal extent, but the significance of its impact is magnified as it affects a large proportion of an extremely rare habitat. Using the language of the Environmental Protocol, the impacts of such chemicals in the Antarctic environment are neither "minor" nor "transitory" (see Pineschi 2001), and without active remediation and further changes in management practices, localized chemical contamination will continue to have a significant and long-term impact both on the environment and on scientific research.

Chemical contamination associated with on-going sewage disposal is of growing concern. Hale et al. (2008) found that contemporary sewage management practices at McMurdo Station and Scott Base are insufficient to prevent the local dispersal and accumulation of PBDE. These types of contaminants, like the more commonly known globally-dispersed persistent organic pollutants, such as dichlorodiphenyltrichloroethane (DDT) and hexachlorobenzene, are important contaminants in the Antarctic because they are highly persistent, bioaccumulate and are toxic (Weber \& Goerke 2003, Goerke et al. 2004). PBDE derived from materials on station that were treated with flame retardants were found in dust, wastewater treatment sludge, and sediment and fish immediately adjacent to the sewage outfall. Hale et al. (2008) found that levels of PBDE in these fish are comparable to urbanized areas in North America, and concluded that wastewater maceration alone, as allowed under the Environmental Protocol, is permitting significant PBDE and other chemical contamination.

Other minor sources of local contamination include blown cement dust (Adamson et al. 1994), airborne pollution from exhaust emissions and incineration (O'Brien et al. 2004), and isolated contamination events associated with our everyday presence in Antarctica. Near-shore sediments in Winter Quarters Bay, McMurdo Sound have also been found to be contaminated with butyltin, probably as a result of abrasion of antifouling paint from the hulls of icebreakers or from ship groundings (Negri et al. 2004).

Several detailed chemical studies have attempted to fingerprint the source of contaminants or to use chemical signatures to delineate the timing of contamination or rates and mechanisms of degradation. For example, Townsend \& Snape $(2002,2008)$ used stable lead isotopes to document the distribution of Australian-derived lead contamination adjacent to Casey Station (constructed and operated by Australia since 1969), and to differentiate Australian- and American-derived lead sources adjacent to the nearby abandoned Wilkes Station (constructed by the US in 1957 and operated by Australia between 1961 and 1969). For fuel spills, Snape et al. (2005) and Rayner et al. (2007) used chemical fingerprints to differentiate between multiple spill sources where liability (and subsequent payment) was 
ultimately determined based on the extent of specific spill events. The fingerprinting approach has also been extended to monitoring natural attenuation rates and differentiating between various processes of degradation, such as evaporation, biodegradation and water washing, and for determining the efficacy of various remediation treatments (e.g. Gore et al. 1999, McIntyre et al. 2007, Revill et al. 2007).

\section{Longevity of chemicals and their ecological impacts}

Apart from fuel spills that occur in high-energy marine environments, where dispersal is rapid, research findings show that chemical contamination is long-lived in Antarctica. Gore et al. (1999) described fuel spills from the Bunger Hills that were virtually unaltered after more than 10 years in the ground. Snape et al. (2006) and Revill et al. (2007) found that spills at Casey Station were variably weathered and that evaporation caused substantial losses immediately following the event but, after that, the fuel half-life was on the order of decades. Similarly, Aislabie et al. (2001) described enhanced populations of hydrocarbon-degrading microbes more than 30 years after hydrocarbon contamination. Several studies have used recently developed genetic tools to describe the impacts of fuel spills on microbial communities and relate the impacts to contamination (e.g. Evans et al. 2000, Aislabie et al. 2001, Delille et al. 2004). The unpublished results of a long-term oil-spill experiment undertaken at Casey Station by Stark and co-workers indicates that near-shore communities at several trophic levels remain significantly affected five years after the pollution event (J. Stark, Australian Antarctic Division, personal communication 2008). The longevity of contamination is also probably to be influenced by the volatility of the chemical and the substrate on which it is deposited.

Recent studies have demonstrated that chemical contamination has caused ecological impacts at many different trophic levels, from bacteria to vertebrates (e.g. Evans et al. 2000, Stark et al. 2003c, Negri et al. 2006). For example, increased numbers of hydrocarbon-degrading bacteria (e.g. Rhodococcus, Acinetobacter, Pseudomonas, and Sphingomonas) and decreased microbial community diversity in soils have been observed, as have higher occurrences of pathological anomalies in fish (Evans et al. 2000, Aislabie et al. 2001). Marine sediments contaminated with hydrocarbons and heavy metals display greater abundance of polychaetes and gastropods compared to uncontaminated sediments, although the response is location dependent (e.g. Stark et al. 2003c).

Several studies have found that scales of patchiness, of both physical-chemical properties and biological diversity, are high in the Antarctic (Stark et al. 2003a, 2005, Gasparon et al. 2007). Manipulative experiments have been particularly useful in demonstrating cause and effect of chemical contamination (Stark et al. 2003c, Thompson et al. 2007). However, one of the major difficulties for highly contaminated sites affected by multiple contaminant sources, such as Winter Quarters Bay or the sites around Casey Station, is that determination of the precise cause and effect of contamination is difficult. For example, Evans et al. (2000) studied the effects of contaminants on fish in and around Winter Quarters Bay. They concluded that metal contamination had only a limited effect on fish, but that observed changes in the pathologic condition of fish were more likely to be due to organic contaminants such as polycyclic aromatic hydrocarbons (PAH) and PCBs. Crockett \& White (2003) advocate that the uncertainty associated with attributing effects to specific pollutants should be a focus of future research because it could help refine management or remediation to focus on the most potent chemical sources.

\section{On-site remediation}

The importance of managing contaminated sites was emphasized in the Environmental Protocol through its Annex III, Waste Disposal and Waste Management. Article 1 of Annex III requires that past and present waste disposal sites on land and abandoned work sites of Antarctic activities shall be cleaned up by the generator(s) of such wastes and the user(s) of such sites. This obligation does not require the removal of any structure or waste material in circumstances where the removal by any practical option would result in greater adverse environmental impacts than leaving the structure or waste material in its existing location.

The high costs, logistical difficulties, environmental risks and political sensitivities make bulk earth extraction, transport and disposal (dig-and-haul) an unattractive proposition. The challenge for research scientists and engineers is to develop robust low-cost alternatives that can be applied on site. A range of techniques has recently been investigated, including multistage water treatment systems, permeable reactive barriers, and bioremediation of petroleum hydrocarbons (see Snape et al. 2001a, Northcott et al. 2005, Filler et al. 2008 and references therein). Bioremediation could have the greatest potential cost saving over dig-and-haul if it can be developed to work as well on site as in the laboratory. New Zealand, USA, Argentina, Australia, UK and France have all investigated the bioremediation potential of indigenous microorganisms under a range of engineering conditions (see Aislabie $e t$ al. 2004, Walworth et al. 2008 and references therein). Treatment by such means will probably take longer, but provided off-site dispersal can be controlled, bioremediation offers a low-cost alternative strategy.

\section{Quantitative ecological risk assessment}

The need for objective risk assessment information that is specifically relevant to the Antarctic environment is well 
illustrated by the difficulties encountered when designing remediation programmes with an absence of clean-up criteria (Stark et al. 2006, Snape et al. 2008). Others have also noted the paucity of quantitative environmental risk data for the Antarctic (Chapman \& Riddle 2005). Following methodologies developed in Canada and Australia, Snape et al. (2008) proposed a weight-of-evidence approach to derive trigger levels and set remediation targets for soils. The approach uses data from chemical modelling, ecotoxicology and ecological community impacts to derive a conservative table of trigger values (minimum values at which reaction or response is required by managers) for a particular contaminant. The idea is that ecosystem health will be protected from contamination if chemical levels stay below the trigger value. The physical characteristics of Antarctica, such as low temperature, seasonal snow or sea ice cover, and limited soil development, influence how contaminants behave and interact with biota in ways that can influence ecological risk. Trigger values derived from some temperate organisms may be too high, i.e. not conservative enough to protect Antarctic or sub-Antarctic soil ecosystems (e.g. Schafer et al. 2007, Snape et al. 2008). Antarctic organisms take much longer to develop than similar temperate species. Sensitive development stages last longer, and organisms are especially vulnerable to chemical contamination over a longer period of time. King \& Riddle (2001) found that, when the Antarctic sea-urchin (Sterechinus neumayeri (Meissner)) is exposed to copper and cadmium during the sensitive larval stage of reproduction, its EC50 values (the concentration of a contaminant that creates an effect in $50 \%$ of the test organisms) are approximately $1 / 5$ to $1 / 10$ th of the values found in similar temperate species if the test is allowed to run to the same stage of development. However, it remains the case that very few comprehensive ecological studies have been undertaken that can be used directly to feedback into a trigger value.

Without doubt, Antarctica lags far behind other global regions regarding the existence of environmentally relevant data for risk-based decision-making (Chapman \& Riddle 2005, Chapman et al. 2006). In accord, Crockett \& White (2003) called for focussed research to quantify contaminated sediment deposition rates, improved delineation of sources and fluxes into and out of Winter Quarters Bay, and to identify specific contaminants that are responsible for apparent toxic impacts. These research needs are common to sites adjacent to all other coastal stations, and such information could help manage contaminated sites that are difficult and extremely expensive to remediate.

\section{Contamination from sewage}

Disposal of the sewage waste generated by the estimated 4000 summer and 1000 wintering personnel in the 37 permanent and 16 summer-only active stations is a challenge for Antarctic Treaty nations (Gröndahl et al. 2008). Annex III to the Environmental Protocol recommends that, to the maximum extent possible, sewage should not be disposed on to sea ice, ice shelves or grounded ice sheet, unless in deep ice pits when this is the only practicable option. It further requires that sewage from coastal stations housing more than 30 people is to be treated before being disposed of in the sea. Without the ocean to dilute and disperse sewage waste, inland stations (including those on permanent ice shelves) face significant additional technical challenges for sewage disposal. Connor (2008) reported that, since the entry into force of the Environmental Protocol, the level of sewage treatment applied at stations varies considerably. Many countries do no more than is required of them by the Environmental Protocol whereas others have taken the decision to treat their sewage to levels that exceed their own national standards. Sewage waste and 'grey water' originate from station toilets, laundry facilities, accommodation and cooking areas and may contain faeces, urine and associated nutrients, microorganisms (including potential pathogens), organic material (toilet paper and food waste), detergents, heavy metals, hydrocarbons and desalination plant brine. Fishing, tourist, research and re-supply vessels also generate sewage, but this should be discharged into water more than 12 nautical miles from the coast according to Article 6 of Annex IV to the Environmental Protocol, and is unlikely to have a significant environmental impact. The presence of shipping vessels at any given location is relatively short, but breaches to the provision on sewage discharge location could be a concern. Nevertheless, with the exception of McMurdo Station, which has a peak capacity of well over 1000 people, shipping represents the most common, large local density of people in Antarctica, as individual ships carry typically hundreds but sometimes as many as 3000 people.

\section{Ecological impacts}

In the last decade, most sewage impact studies have focussed on benthic invertebrates, particularly near McMurdo and Casey Stations (populations of approximately 1000 and 50, respectively). Before sewage treatment started at McMurdo in 2003, long-term release of untreated sewage led to significantly reduced benthic community abundance around the location of the outfall. However, at all but the most contaminated sites, biodiversity was equal or greater than at control sites (Conlan et al. 2004). Reduced assimilation of organic sewage material near the outfall was caused by the formation of an anaerobic microbial biofilm that caused avoidance by megafauna scavengers (Kim et al. 2007). Using a technique that examined carbon- and nitrogenisotope ratios in sewage, sediments and invertebrates, Conlan et al. (2006) suggested that generalist benthic 


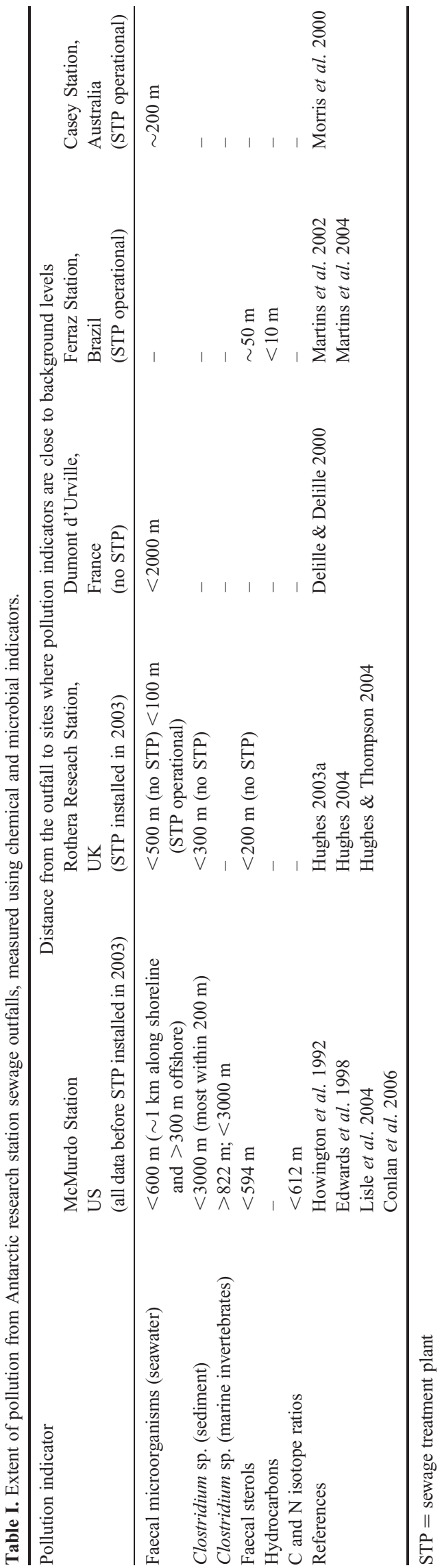

feeders could be used as biomonitors for sewage contamination at sites across Antarctica. Studies at Casey Station showed that even comparatively low volumes of sewage could affect the near-shore marine environment, with impacted sites generally having lower species richness, biodiversity and variability compared with control sites (Stark et al. 2003a). Evidence suggests that sewagederived heavy metals may impact upon soft-sediment assemblages (Casey Station, Stark et al. 2003b) and the clam Laternula elliptica (King \& Broderip) (Rothera Research Station, Lohan et al. 2001).

Comparatively little work has been done on the effects of sewage on other biological groups. In experiments, it has been shown that sewage may cause genotoxic effects and pathological anomalies in Antarctic fish (Van Ngan et al. 2007). Whilst a comparison of heavy metal effects between Winter Quarters Bay and an almost pristine site suggests that levels of heavy metals found in sewage may have little direct effect on fish (Evans et al. 2000). A recent report of $E$. coli from two fur seal pups suggest that pathogenic microbes can be ingested by marine mammals but it is not yet clear what the pathway might be (Hernandez et al. 2007). Effects upon indigenous marine microorganisms are little understood, although George (2002) showed that Antarctic marine microorganisms could break down detergents commonly found in sewage but at a lower rate than in temperate locations.

\section{Dispersal}

Sewage contamination levels around outfalls depend upon the biological and physical environmental characteristics, the volume of sewage released and the degree of treatment. The extents of several Antarctic station sewage plumes were published before the implementation of the Environmental Protocol (Hughes 2004 and references therein). However, since 1998, sewage plume extents, measured using faecal microorganisms, have been published for McMurdo (Edwards et al. 1998), Casey (Morris et al. 2000), Dumont d'Urville (Delille \& Delille 2000) and Rothera Stations (Hughes 2004, Hughes \& Thompson 2004). Both chemical (faecal sterols and hydrocarbons) and microbial (faecal coliforms, Clostridium perfringens and viruses) sewage indicators showed that contamination was generally localized around the outfalls (see Table I). Indeed, Santos et al. (2005) found elevated metal concentrations in marine sediments only in the immediate vicinity of Comandante Ferraz Station sewage outfall. Ensuring optimal operational performance of wastewater facilities is notoriously difficult, particularly if sewage treatment plants are installed, making on-going sewage impact monitoring essential (Hughes \& Blenkharn 2003, Gröndahl et al. 2008). Ecological impacts are probably modulated by the mixing regime of the discharge area. They are likely to be more marked if discharge is in 
shallow waters or in an enclosed bay, while strong currents and rapid mixing are likely to dilute impacts.

Environmental factors affecting numbers of viable faecal coliform bacteria in sewage plumes include: the level of microbial input by the station population and transient local wildlife, seawater temperature and salinity flux and dilution effects by local currents and solar ultraviolet radiation (UV) (Hughes 2003a). The negative effects of UV on microbial viability are increased by high seawater oxygen concentrations, but are reduced by UV attenuation caused by increasing water depth, sea ice presence and algal blooms. Antarctic solar radiation also naturally reduces bacterial cell viability with increasing exposure time and decreasing radiation wavelength, ozone column depth, cloud cover and solar zenith angle (Hughes 2005).

Not all human activities are located at the coast. Inland, sewage is generally disposed of either in "sewage bulbs" in ice beneath stations (e.g. Amundsen-Scott Base, Halley Research Station), while field parties may bury faecal waste in shallow snow pits, crevasses, or dispose of it directly into the sea when in coastal locations. The legacy of sewage disposal can be long-term. Using molecular techniques, bacterial genetic material from sewage organisms was detected many years after deposition (Sjoling \& Cowan 2000). Spore-forming strains such as Bacillus and Clostridium sp. were shown to survive up to 40 years (Hughes \& Nobbs 2004), but faecal coliforms were vulnerable to ultraviolet radiation and desiccation (Hughes 2003b). On the Antarctic Peninsula, regional warming has reduced snow cover around some nunataks and coastal areas, resulting in previously buried (and long forgotten) faecal material melting out of the ice (see examples in Hughes \& Nobbs 2004). Some Antarctic operators do not permit dumping of faecal waste in the field, and return it to research stations for disposal, although this itself raises other potential environmental and safety concerns, such as the risk of spills and further contamination during storage in the field, and health and safety concerns for field and logistics staff who are handling and transporting the waste. Antarctic Specially Protected Area (ASPA) management plans generally stipulate that sewage disposal is forbidden within the protected area. While the Environmental Protocol encourages the removal of waste from field camps, the disposal of sewage within the vast majority of Antarctica is still possible, without breaching the terms of Environmental Protocol. The long-term potential impact of sewage is not known largely because it has not been systematically investigated.

\section{Human disturbance on flora and fauna}

The Antarctic terrestrial biota is species poor, lacking representatives of many higher taxonomic groups (Convey 2007). Faunal communities consist of invertebrates
(Diptera - two species, Acari, Collembola, Nematoda, Rotifera, Tardigrada and Protista), and plant communities largely of cryptogams (mosses, liverworts, lichens), with only two higher plants present. Biodiversity and community complexity generally decrease with increasing latitude and environmental severity, although the detailed pattern is considerably more complex (e.g. Clarke 2003, Chown \& Convey 2007, Peat et al. 2007). For most of these groups, fine-scale survey data are lacking and large gaps remain in knowledge of their biology and biogeography. Continental Antarctica exhibits faunal communities which are amongst the simplest on the planet (Freckman \& Virginia 1997), uniquely in some areas lacking even Nematoda (Convey \& McInnes 2005). Most invertebrates are thought to be microbivores or detritivores, with true herbivory rare and predation insignificant, although few rigorous autecological studies have been completed (Hogg et al. 2006). Minimal information is available for most microbiota. The application of molecular biological techniques is now leading to an increase in our perception of diversity within continental and maritime Antarctica (e.g. Lawley et al. 2004, Boenigk et al. 2006, Yergeau et al. 2007), but spatial coverage remains very limited.

In contrast, the Antarctic marine ecosystem supports a large number of species. Primary production can reach very high levels and is intensely seasonal following the availability of light and the sea ice cycle. Copepods, salps and euphausids are the dominant herbivores, with Antarctic krill (Euphausia superba Dana) playing a central role in the pelagic marine ecosystem and crystal krill (E. crystallorophias Holt \& Tattersall) doing the same in extensive neritic habitats, such as the Ross and Weddell sea shelves, sustaining large populations of predators, including squid, fish, seabirds, seals and whales (Clarke \& Harris 2003). Nineteen species of baleen and toothed whales migrate to feeding grounds in the Southern Ocean each year between November and May, as do a number of seabird species. While birds and seals spend the majority of their lives feeding at sea, many spend months at a time along the coast on sea ice, or more often, on ice free land to breed or moult.

The increase in scientific, logistic and tourist activities apparent over the last several decades in the Antarctic clearly leads to potentially much higher cumulative impacts on the environment, magnified on land, as described above, by the very small total area of ice free ground in Antarctica. Human activities can affect flora and fauna at many different levels of biological organization, ranging through habitats, communities, populations and individuals. Impacts can range from minor and transitory to severe and long-term.

\section{Impacts on Antarctic flora}

Very few scientific reports have described the effects of human disturbance to Antarctic terrestrial vegetation 


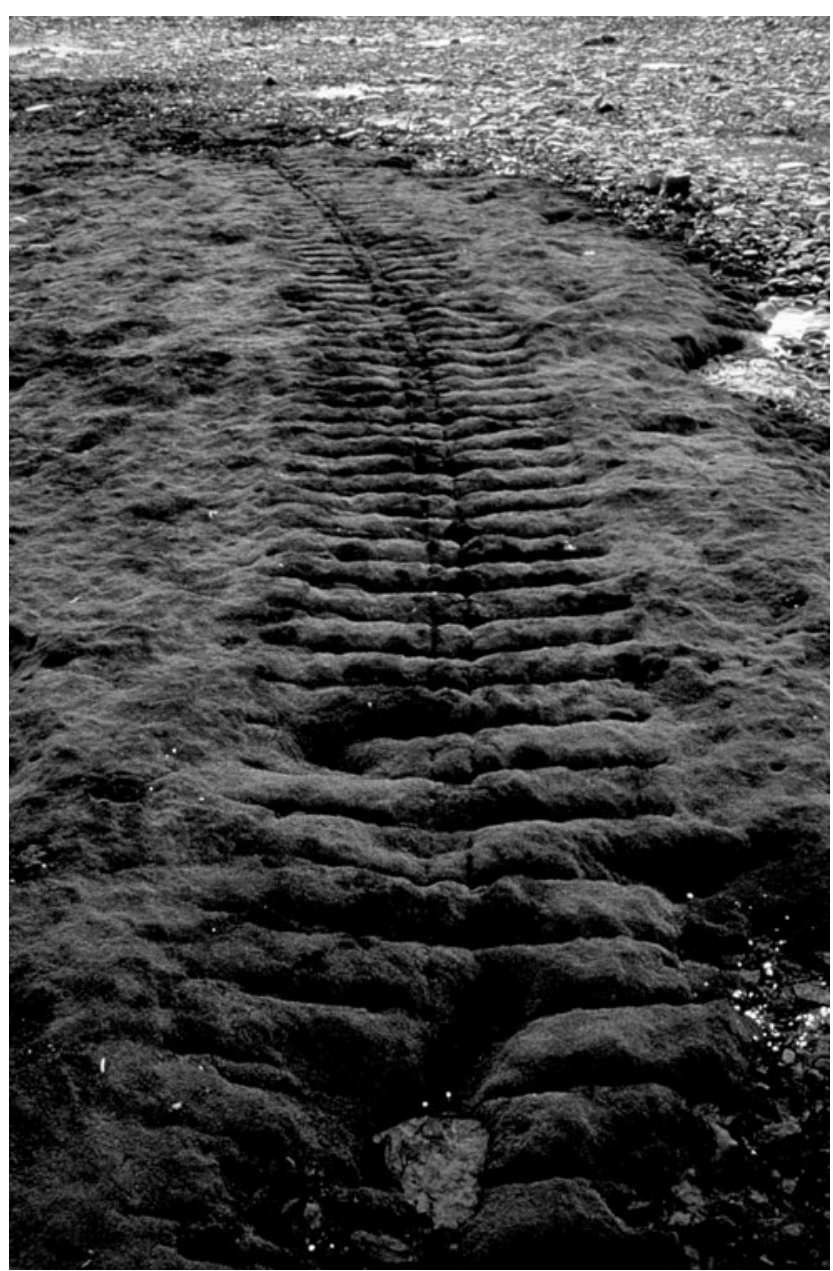

Fig. 2. Bulldozer tracks over a moss patch on Fildes Penninsula. (Photo by Colin Harris)

(Poland et al. 2003). It is our opinion that this is likely to reflect a historical lack of coordinated scientific study rather than a lack of disturbance per se. It has been stated that direct impacts on Antarctic terrestrial ecosystems are relatively minor (Huiskes et al. 2006); however, such simple statements can lead to possible misconception. It is true in an absolute sense that, by metrics such as the area of ground affected or the number of humans involved (direct "footfalls"), impacts can be described as restricted. On the other hand, only about $0.34 \%$ of the Antarctic continental area is ice free, and it is here that most research stations are built. Human activities inevitably compete with terrestrial ecosystems, as well as seals and seabirds, for the small areas of ice free ground available, intensifying the pressure on individual sites at a local scale.

It is tempting to propose that the general lack of scientific documentation of impacts to vegetation and soils over the past decade reflects a decrease in human disturbance to terrestrial environments since the Environmental Protocol came into force, but there have been few objective studies generating data to either prove or disprove this assertion.
The available information on impacts over the past several decades is discussed below, concentrating on the period after 1998 .

Without doubt, disturbance to terrestrial ecosystems by people has been important where station infrastructure and vegetation are located in the same vicinity. Several studies prior to 1998 reported significant vegetation impacts associated with stations and infrastructure, including physical destruction of mossbeds and contamination of lichens and mosses with cement dust and metals (Fig. 2; Chen \& Blume 1997, Hansom \& Gordon 1998, ASOC 2004, Bargagli 2005 and references therein). Ohtani et al. (2000) monitored algal species and soil condition around Syowa station for six years and noted that increased growth of the native macroscopic alga Prasiola crispa could be used to indicate soil eutrophication due to human activities. Bargagli (2005) noted that contamination by air pollutants from stations is usually limited to a few kilometres or a few hundred metres range, and that some species of lichens and mosses can be used as reliable biomonitors in this context since they are long-term indicators of persistent atmospheric pollutants. Where there is a high concentration of stations established by many different nationalities, for example, on Fildes Peninsula on King George Island, there are many areas of damaged vegetation (ASOC 2004, United Kingdom et al. 2005, Peter et al. 2008).

In the sub-Antarctic, studies on human-formed tracks have demonstrated that trampling has considerable impact on plant species and soils. Results from South Georgia (Bird Island, Hughes 2006), Macquarie Island (Scott \& Kirkpatrick, 1994), and Gough and Marion islands (Gremmen et al. 2003) were very similar. Impacts varied according to the nature of the vegetation communities and soils and included track widening, vegetation degradation and/or species replacement, as well as alteration of soil compaction properties. Very few studies on impacts of trampling on Antarctic vegetation and soils have been undertaken, although vulnerability to even low levels of disturbance is recognized (Beyer \& Bölter 2002 and references therein). On Cuverville Island, Antarctic Peninsula, de Leeuw (1994) found that simulated trampling by a group of 50 persons on moss peat vegetation for one week resulted in damage to the extent that recovery was not possible during the same growing season. Tejedo et al. (in press) conducted a series of trampling experiments on vegetation-free soils in the South Shetland Islands as a contribution towards Scientific Committee on Antarctic Research (SCAR) the Council of Managers of Antarctic Programs (COMNAP) recommendations for minimizing scientists' impact in Antarctica (National Science Foundation/COMNAP/SCAR 2005), and documented changes in soil compaction properties and invertebrate populations under different trampling regimes. Through experimental work and examination of existing humanformed paths, it was concluded that even the lowest 
experimental impact (100 pedestrian transits) generated a significant effect on soil compaction properties and soil invertebrates, and systematic monitoring would be required to avoid impacts exceeding their recovery capacity (Tejedo et al. in press). On continental Antarctica (McMurdo Sound and Dry Valleys), where vegetation may be limited to lichens, cyanobacterial mats and microbial cryptobiotic soil crusts, Campbell et al. (1998) found that tracks formed in sandy gravel soils with as few as 20 pedestrian transits, and human impact from ground disturbances were visible up to 30 years later.

\section{Impacts in the vicinity of research stations}

In view of the scarcity of reports of vegetation impacts in the scientific literature since 1998, Antarctic Treaty Inspection Reports - reporting the inspections of Antarctic research stations - provide one of the few sources of information documenting recent vegetation impacts in the vicinity of stations. Seven Inspection Reports available since 2001, four of which include inspections of stations where vegetation issues are mentioned, indicate to some extent that impacts may have reduced since the entry into force of the Environmental Protocol, although their limitations (Harris 1991) mean that consistency of reporting cannot be assumed. Two of the Inspection Reports cover stations on the western side of the Antarctic Peninsula (United States 2001, United Kingdom et al. 2005), one on Ross Island (Australia 2005) and the other in Dronning Maud Land (Norway 2001). In general they indicate a widespread and high level of awareness of the measures and requirements of the Environmental Protocol amongst the stations inspected, including the need to protect vegetation, although this was not always seen to be translated into practice. There is also some inconsistency in reporting detail - for instance damage reported to moss beds on King George Island in 2005 (United Kingdom et al. 2005) was not mentioned in the previous inspection in 2001 (United States 2001), but it is not possible to state whether the damage had not been observed in 2001, or that it had occurred in the interim.

\section{Impacts at popular visitation sites}

Occasional anecdotal comments in the scientific literature relating to tourist visits to Antarctica prior to 1998 indicate that a certain level of trampling of vegetation probably occurred from tourists during that time (Chen \& Blume 1997 and references therein, Hansom \& Gordon 1998). Rigorous scientific data obtained either in this period or more recently are largely lacking. Naveen (2004) reported results from a ten-year study monitoring impacts at tourist sites on the Antarctic Peninsula since 1994; the report measured a number of faunal and floral indicators, but left unclear was whether any impacts were observed.
The tourism industry organization - The International Association of Antarctic Tour Operators (IAATO) - was formed in 1991 and currently represents over 90\% of tour companies operating in Antarctica (IAATO 2008). IAATO has collaborated with the Antarctic Treaty Consultative Parties (ATCPs) to produce the document Guidance to Visitors (ATS 1994), its members have demonstrated an apparently high level of compliance to both its own and Environmental Protocol requirements (IAATO 2007), and it continues to collaborate with the ATCPs to produce Site Guidelines for Visitors for specific sites. Site guidelines have been adopted by the ATCPs for 18 of the most-visited sites in the Antarctic Peninsula area (ATS 2008a). Of these 18 sites, only Barrientos Island and Half Moon Island, both in the South Shetland Islands, have "known impacts" to vegetation, while 11 have "potential impacts" to vegetation (including the sites with known impacts). Five sites have "closed areas" partly due to sensitive vegetation, and for two sites, guided walking routes are recommended to avoid vegetation trampling. Sixteen of the 18 sites support significant vegetation, and these guidelines include clear instructions to avoid walking on any vegetation susceptible to disturbance. At Barrientos Island, successive years of visits by tourist groups had resulted in "the erosion of multiple footpaths through vegetation between the eastern and western end of the island" (ATS 2008a). As a solution, the site guideline describes a new guided walking route which avoids vegetation trampling. Along with the other 17 Site Guidelines, it provides a good example of collaborative practical problem solving between the ATCPs and the tourist industry to minimize vegetation impacts.

\section{Disturbance to fauna}

Antarctic birds and seals are at a disadvantage in regard to human disturbance. Many species spend significant periods on land or ice during breeding, haul out and moult. However, their escape response is not highly developed, compared with similar species elsewhere, as land-based predators including humans have not been part of their evolutionary history. Only penguins and other birds are sensitive to land-based predators, such as skuas and giant petrels, and are very defensive of eggs and young (de Villiers 2008). Human approach may lead to direct or indirect consequences. For example, a bird may exhibit behavioural and physiological changes in accord with a stress response, which in turn, if sustained, could have a negative impact on reproduction and survival. Visitors could disrupt a penguin colony. Disturbed parents may abandon their eggs or young, making them vulnerable to predators. de Villiers (2008), in a recent review of research over the last two decades on the effects of human disturbance on wildlife in the Antarctic and sub-Antarctic, concluded that at some locations and for certain species, 


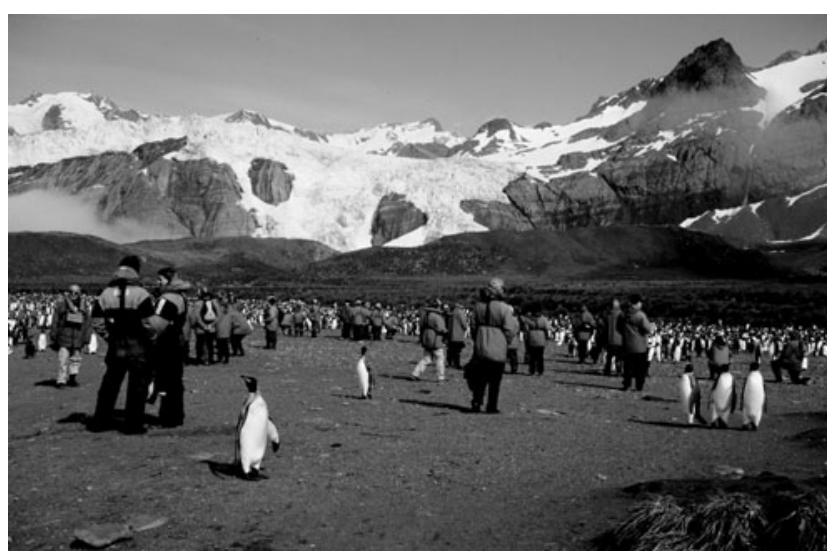

Fig. 3. Tourists and penguins at Gold Harbour, South Georgia. (Photo by Simone Pfeiffer)

the disturbance associated with general human activities has little apparent effect on wildlife population trends, e.g. for Adélie penguins (Pygoscelis adeliae Hombron \& Jacquinot) at Palmer Station and King George Island (Fraser \& Patterson 1997, Carlini et al. 2007), and gentoo penguins (Pygoscelis papua Forster) at Port Lockroy (Cobley \& Shears 1999), while, at other sites and for some species, human activities have been implicated in population declines, e.g. southern giant petrels (Macronectes giganteus (Gmelin); Woehler et al. 2003, Micol \& Jouventin 2001) and snow petrels in East Antarctica (Pagodroma nivea Forster; Micol \& Jouventin 2001). Bricher et al. (2008) reported that proximity to human activities is a significant driver of the population trends of Adélie penguin colonies in the vicinity of Casey Station in East Antarctica. The majority of sub-colonies with decreasing populations are located closest to the station, although further investigations are needed in order to separate the potential contribution from station-related activities, such as noise and particulate emissions, from the effects of visits to the colonies. Cumulative impacts of different activities on Antarctic wildlife can be especially important as human activities, arising both from tourism and national operator activities, concentrate in and around the station grounds, on roads, and in areas with easily accessible concentrations of fauna and flora (Fig. 3) (Pfeiffer et al. 2006, Peter et al. 2008).

\section{Pedestrian approach}

When approached by humans, Antarctic wildlife may alter their behaviour. Studies to determine minimum appropriate approach distances in seabirds began in the early 1990s and have continued (e.g. Pfeiffer \& Peter 2003, Martin et al. 2004, de Villiers et al. 2006, Burger \& Gochfeld 2007, Holmes et al. 2008). Altered behaviour in birds may result in energetic and/or time costs (Burger \& Gochfeld 2007). Some birds display elevation of heart rate (e.g.
Weimerskirch et al. 2002, de Villiers et al. 2006) or increased expression of stress hormones (e.g. Fowler 1999), but demonstration of direct fitness consequences of these responses remain elusive. Gentoo penguins (Jouventin et al. 1984, Holmes 2007) and southern giant petrels (Jouventin et al. 1984, Woehler et al. 2003, Pfeiffer \& Peter 2004) are especially sensitive to human disturbance and repeated approaches to breeding wandering albatrosses (Diomedea exulans Linn.) influenced their chick survival (Wheeler et al. 2008), but species-specific sensitivity varies according to site [consider gentoo penguins at Macquarie Island (Holmes 2007) and at Port Lockroy (Muller-Schwarze 1984, Cobley \& Shears 1999, cited in de Villiers 2008)].

Whether visitor impacts lead to reduced recruitment and population abundances of seabirds over longer time scales is difficult to judge because habituation may occur (Cobley \& Shears 1999, Otley 2005) and individuals may relocate to other sites. It has, for instance, become evident that the behaviour and the physiology of individual animals can be affected strongly by parameters such as visit duration, visit frequency and intensity and duration of contact by researchers (e.g. Salwicka \& Stonehouse 2000, Weimerskirch et al. 2002, Pfeiffer 2005). This can have severe consequences, potentially lengthening foraging trips and sometimes resulting in abandonment of offspring (e.g. Wilson et al. 1989). Species, however, vary in their susceptibility to human disturbance, although habituation typically only takes place if disturbance is regular and predictable (de Villiers 2008). Van Polanen Petel et al. (2007) reported that, among Weddell seals (Leptonychotes weddellii Lesson) and their pups on Windmill Islands in East Antarctica, habituation took place over ten approaches within two hours, while irregular visits did not result in any sign of habituation. At Dumont d'Urville Station, Adélie penguins have been observed to nest underneath station buildings, sheltered from harsh winds, despite high human frequentation (Y. Ropert-Coudert, personal communication 2008), as do gentoo penguins at Port Lockroy. Pfeiffer (2005) studied effects of human visits of between 5 and $100 \mathrm{~m}$ to breeding and resting southern giant petrels and skuas. Scientists triggered the strongest reactions when they checked nests. However, unguided station members and tourists who were walking off usual paths also caused an increase in flight and defensive behaviour, and the reactions of birds varied according to each individual's degree of habituation to people.

\section{Handling of animals}

Some scientific research requires catching animals, handling them and fitting external equipment, such as leg bands, flipper tags, tracking devices or 'crittercams'. In some cases more invasive procedures are involved, including sampling of stomach contents by water offloading and the implantation of various types of biological and 
environmental loggers. Devices attached to the body of an aquatic animal compromise the animal's streamlining and thereby induce a modification to the animal's foraging performances (e.g. Ropert-Coudert et al. 2007). This, in turn, may lead either to a decrease in the food load captured or, if the load is kept constant, to an increase in the energy expenditure of the animal. Similarly, putting bands on penguin flippers for identification has led to increased energy expenditure during swimming in the laboratory, physical injury, and mortality during moult (e.g. Jackson \& Wilson 2002, Gauthier-Clerc et al. 2004). On the other hand, it has been shown in the field that while foraging trips increase slightly in length, food loads brought back to the chick also increase among banded compared to unbanded Adélie penguins, indicating the complexity of the issue (Dugger et al. 2006, see also Ballard et al. 2001). In some recent studies, flipper bands have been replaced with subcutaneous transponders, though the information gained is not usually equivalent. However, transponders, if not applied judiciously, could also compromise survival in some individuals by introducing bacteria and causing infection (Clarke \& Kerry 1998). Tracking devices are often attached to the bodies of flying seabirds, such as albatrosses and petrels, and subsequent nest abandonment and extended foraging periods by the birds in question have been observed. However, by limiting the weight of the device to less than $3 \%$ of the body mass of the birds, the likelihood of these negative impacts has been reduced (Phillips et al. 2003).

\section{Construction, noise and light}

The construction of infrastructure could potentially result in significant disturbance to Antarctic wildlife. Peter et al. (2008) recorded a reduced breeding activity of Wilson's storm petrels (Oceanites oceanicus Kuhl) during and after the recent extension of the Chilean airstrip on Fildes Peninsula on King George Island. In the case of the construction of an airstrip at Pointe Géologie in East Antarctica between 1984 and 1992, two islands were destroyed, together with $10-35 \%$ of the nesting sites of Adélie penguins, cape petrels (Daption capense Linn.) and snow petrels. Breeding pairs were removed from their nesting areas by station personnel or left the area on their own. Monitoring over a period of 14 years showed that, by 1999, the populations most heavily affected by the destruction of their habitats have re-established themselves to levels prior to disturbance (Micol \& Jouventin 2001).

Noise and visual intrusion arising from aircraft operations can also disturb Antarctic wildlife (Hughes et al. 2008, Harris 2005). According to de Villiers (2008), the impacts of aircraft operations on wildlife range from insignificant (e.g. Burton \& van den Hoff 2002) or minor behavioural changes (Giese \& Riddle 1999, Southwell 2005), to increases in heart rate and temporary nest desertions resulting in some egg or chick mortality (Wilson et al. 1991), multiple nest desertions (e.g. Sladen \& Leresche 1970) and mass panic and the resulting death of thousands of birds (Rounsevell \& Binns 1991). For example, Giese \& Riddle (1999) observed behavioural reactions of emperor penguin (Aptenodytes forsteri Gray) chicks to air traffic. All chicks demonstrated increased vigilance and the majority of the animals started to walk or run away at the approach of a helicopter at an altitude of $1000 \mathrm{~m}$. Hughes et al. (2008) also found a significant change in the behaviour of breeding king penguins (Aptenodytes patagonicus (Miller)) during helicopter overflights at altitudes between 230 and $1768 \mathrm{~m}$. Generally, as the helicopter approached, many nonincubating adults and juveniles walked away from the approaching helicopter while all incubating birds stayed on their nests. Pfeiffer (2005) showed a stronger response of southern giant petrels and skuas to aircraft over-passes following seldom-used routes compared to main routes. The decrease in the southern giant petrel population at Point Géologie has been higher than that in other populations in East Antarctica, and has been attributed, at least in part, to the higher level of human disturbance there, notably the helicopter landing zone, which is only $40 \mathrm{~m}$ from the traditional main breeding area (Micol \& Jouventin 2001). However, in some cases habituation to air traffic may occur (Cobley \& Shears 1999, Otley 2005, Hughes et al. 2008).

Underwater, marine vertebrates are particularly sensitive to anthropogenic noise. The noise associated with all forms of transport is likely to be audible to animals under the sea surface, and underwater explosions can in some cases cause mortality of penguins (Brown \& Adams 1983, van Polanen Petel et al. 2006, cited in de Villiers 2008). Whale watching from ships or small boats can also disturb marine mammals (COMNAP 1999). It has been suggested that high source-level hydroacoustic equipment poses some risk to cetacean hearing and could potentially lead to auditory damage. Equipment of the strength and frequency implicated elsewhere in the world is not used in the Antarctic, although lower intensities may generate avoidance behaviour (SCAR 2006a, Kremser et al. 2005).

Lights on ships at night can disorient birds, and bird strikes on vessels operating in the Southern Ocean are not infrequent (Black 2005). The level of mortality is generally, but not always, low. The use of deck lights under conditions of reduced visibility in the vicinity of major breeding sites of burrow-nesting petrels, such as the blue petrel (Halobaena caerulea (Gmelin)) and the common diving petrel (Garrodia nereis (Gould)), have led to occasional incidents where hundreds of birds collided with ships overnight, and were found dead or dying on the deck at dawn (Black 2005).

\section{Introduction of non-indigenous species}

The simple terrestrial ecosystems in Antarctica are particularly vulnerable to the various processes of 
contemporary environmental change, which include changes in zoogeographic distributions and colonization by nonindigenous species (e.g. Freckman \& Virginia 1997, Bergstrom \& Chown 1999, Convey 2006). The lack of indigenous diversity allows the occupation of new ecological niches (including currently unrepresented trophic functions and levels), leading to large changes in structure and function in ecosystems. The responses of the indigenous biota to such changes can be constrained by features of their "adversity-selected" life history strategies (Convey 1996) - while well adapted to survive the abiotic environmental extremes of Antarctic terrestrial ecosystems, they generally lack competitive abilities and are vulnerable to increased competition and predation from invading taxa (Convey 1996, Frenot et al. 2005, Convey et al. 2006). This vulnerability is already well demonstrated by the consequences of the presence of a wide range of alien species on the various sub-Antarctic islands (Frenot et al. 2005, 2008, Convey et al. 2006).

\section{Natural and anthropogenically-assisted colonization of Antarctica}

Even with Antarctica's geographical and environmental isolation, it is clear that natural transfer and establishment events take place over evolutionary timescales, both into and out of the region (Clarke et al. 2005, Barnes et al. 2006), via several potential dispersal routes (reviewed by Hughes et al. 2006). At temperate Gough Island in the South Atlantic and sub-Antarctic Marion Island in the Indian Ocean, it is estimated that natural colonization processes have been outweighed by anthropogenic introductions by at least two orders of magnitude over the few hundred years since the islands' discovery (Gaston et al. 2003, Gremmen \& Smith 2004). It is not clear that the same magnification can be applied to colonization of the much more severe Antarctic continental environment, as fewer potential colonists will posseses appropriate pre-adapted biological features (Convey 2008). In the sub-Antarctic, the last two centuries of human contact have seen major changes in the structure and functioning of terrestrial ecosystems (Frenot et al. 2005, 2008, Convey et al. 2006). These changes resulted from the anthropogenic introduction of many non-indigenous plants and animals, both deliberately and inadvertently. The subAntarctic provides a clear warning of the consequences of the establishment of invasive non-indigenous species (sensu Frenot et al. 2005) within the Antarctic continent, which is expected to increase in likelihood under climate change. Although very few non-indigenous species are yet established in the latter region, it is clear that many analogous transfers of biota do occur, with the major vectors including cargo, vehicles, food, clothing and people themselves (Sjoling \& Cowan 2000, Whinam et al.
Table II. The occurrence of established non-indigenous species of terrestrial biota across Antarctic biogeographical zones (updated from Frenot et al. 2005)

\begin{tabular}{lccc}
\hline Biological group & $\begin{array}{c}\text { Entire sub- } \\
\text { Antarctic }\end{array}$ & $\begin{array}{c}\text { Continental } \\
\text { Antarctic }\end{array}$ & $\begin{array}{c}\text { Maritime } \\
\text { Antarctic }\end{array}$ \\
\hline Dicotyledons & 62 & 0 & 0 \\
Monocotyledons & 45 & 1 & 2 \\
Pteridophytes & 1 & 0 & 0 \\
Total non-indigenous & 108 & 1 & 2 \\
$\quad$ plants & 72 & 0 & $2-5$ \\
Invertebrates & 16 & 0 & 0 \\
Vertebrates & & & \\
\hline
\end{tabular}

2004, Frenot et al. 2005, Lewis et al. 2005, 2006, Hughes et al. 2006).

The early years of human activity in Antarctica included many examples of the deliberate import of a range of vertebrates for transport, food and recreational purposes. Such imports are no longer permitted under the Antarctic Treaty. However, on many sub-Antarctic islands (primarily Kerguelen, Macquarie, Marion, South Georgia), the human-mediated introduction of non-native vertebrates (rats, cats, rabbits, sheep, reindeer, mouflon) has led to major negative impacts for nesting birds and their chicks (Frenot et al. 2005). The 1960s and 1970s also saw a number of botanical transplant experiments into Antarctic field locations, particularly at the South Orkney Islands (Smith 1996), assessing the characteristics required of potential colonizing species. Again, such transplants are no longer permitted, and the ATS provides formal mechanisms for controlling the import into Antarctica, handling and subsequent destruction of non-indigenous biota for scientific purposes. However, despite the clear strictures provided under the ATS, there continue to be new instances of angiosperms being deliberately imported into the Antarctic and planted amongst native vegetation. The most clear-cut example occurred around 1997 near Great Wall Station, King George Island, when several grasses, other graminoids and Cerastium sp., were planted in fellfield beside a vehicle track (Smith 2003). These persisted over several years and at least one species (Cerastium sp.) produced several new plants nearby. All plants that could be located were removed in 2005 (H.-U. Peter, personal communication 2008).

\section{Known established non-indigenous species - invertebrates and plants}

The number of instances of non-indigenous species establishing in Antarctica is much lower than that for the sub-Antarctic (Table II), with a total of up to eight species (five proven) known from the former, compared with approximately 200 from the latter. There is no confirmed evidence of any of these persistent non-indigenous species becoming invasive. Additional to the small number of 
species that have become established in Antarctica, there are many anecdotal and a few published instances of nonindigenous biota existing synanthropically (i.e. their survival is only possible in direct association with human activity) within active station buildings over periods of at least several years (Hughes et al. 2005, Greenslade 2006). There are also anecdotal reports of vertebrates kept as "pets" (dogs, birds, fish) and plants on several stations and ships, despite this being prohibited under the Antarctic Treaty.

The five proven examples, established for at least several years, are all in the immediate vicinity of research stations. Three of these are grasses - Poa annua Linn. near Arctowski Station, King George Island (Olech 1996), $P$. pratensis Linn. at Cierva Point near Primavera Station, northern Antarctic Peninsula (Smith 1996) and P. trivialis at Syowa Station, on the continental coast (Japan 1996; this plant was removed in 2007). There are no published studies of population or distribution trends, although there are anecdotal reports that the area occupied by the $P$. annua population at Arctowski Station has expanded in recent years, and there have been some partial attempts at removal. The presence of these species is significant, as both $P$. annua and $P$. pratensis are alien species that are invasive on several sub-Antarctic islands (Frenot et al. 2005, 2008).

The remaining known persistent non-indigenous species are invertebrates accidentally introduced to the immediate vicinity of Signy Station, South Orkney Islands. They were almost certainly introduced during the plant transplant experiments that took place in the 1960s as mentioned above (e.g. Convey \& Block 1996, Dozsa-Farkas \& Convey 1997), although their presence was not recognized until the early 1980s. They are an enchytraeid worm, Christensenidrilus blocki Dozsa-Farka \& Convey, and a brachypterous chironomid midge, Eretmoptera murphyi Schaeffer, and both are otherwise known only from subAntarctic South Georgia. Given the climatic similarity between South Georgia and the South Orkney Islands, these species illustrate the likelihood of successful establishment by species already possessing appropriate preadaptations; the fact that the midge is parthenogenetic further increases this probability (Frenot et al. 2005).

Three further records of non-indigenous Collembola (springtails) have been published from maritime Antarctic sites, but no subsequent assessment has been made of their persistence or status. The cosmopolitan springtail Hypogastrura viatica (Tullberg) has been recorded from the South Shetland Islands (where there are many research stations and much human activity) and Léonie Island in Marguerite Bay (several kilometres from Rothera Station, Adelaide Island) (Greenslade 1995). This species is a particular concern, as it or its congeners have become aggressive species in their invasions of some sub-Antarctic islands, including South Georgia and Macquarie Island (e.g. Frenot et al. 2005, Greenslade 2006). Finally, Folsomia candida (Willem) and Protaphorura sp. have been reported from Deception Island, South Shetland Islands (Greenslade \& Wise 1984). However, their association with human activity is unproven as, although this island is the location of several research stations, it is also geothermally active with areas of heated ground. Such habitats encourage the natural establishment of lowerlatitude taxa otherwise unable to survive in the Antarctic terrestrial environment (e.g. Convey et al. 2000a, Smith 2005).

\section{Microbiota}

The potential significance of microbial introductions to, and subsequent movement within, the Antarctic continent has only recently received any prominence, and very few data are available (Frenot et al. 2005, Convey 2008), other than those relating to the risks associated with sewage (where non-indigenous faecal microbes may infect local bird and marine mammal populations). This is compounded by the difficulty of separating a "newly recorded" microbial taxon that has been introduced anthropogenically, from one that is present naturally and is either cosmopolitan in distribution or has dispersed to the region by natural means. Further, as with some of the invertebrate examples given above, even where evidence of introduction has been proposed, no follow-up studies have assessed status or change (Convey 2008 and references therein). Circumstantial evidence of microbial introductions is provided by studies that compare diversity at human impacted sites (e.g. close to research stations) and pristine areas, assuming that taxa present only at the former are likely to be associated with human activity (e.g. Upton et al. 1997, Azmi \& Seppelt 1998). A particular risk arising from anthropogenic microbial introduction is that of disease in wildlife (Kerry et al. 1999). Proof of disease source is problematic (Frenot et al. 2005) as, even where evidence of disease exposure exists, alternative sources exist, as many Antarctic birds and mammals encounter humans beyond the continent itself during at least part of the year while some, particularly skuas and gulls, regularly forage around lower latitude ports and refuse sites as well as following ships at sea.

Advances in the application of molecular tools promise to improve our ability to identify non-indigenous microbes - for instance, while the classically described Antarctic algal flora is thought to be largely cosmopolitan (Broady 1996), molecular studies of various microbial groups are now showing them to be more distinct and by implication indicative of more ancient evolutionary isolation (Lawley et al. 2004, Boenigk et al. 2006). Molecular methods that ease the detection of specific microbes as "indicators" of human activity are also now available (Baker et al. 2003). 


\section{Intra-continental transfer}

While controlling the risk of establishment of species not already native to the Antarctic continent is clearly important, a separate but fundamentally important risk remains. The Antarctic continent is not a single biogeographical unit and shows considerable intracontinental regionalization (Chown \& Convey 2007, Convey \& Stevens 2007, Convey et al. 2008). Therefore, there are clear threats to regional biodiversity from transfers occurring within the continent. In this context, the strength of the biogeographical boundary across the southern Antarctic Peninsula (the "Gressitt Line" - Chown \& Convey 2007) is significant, as several major higher taxonomic groups (in particular the Acari, Collembola and Nematoda) share no or virtually no species across it.

Molecular biological studies now indicate that many elements of the Antarctic terrestrial biota are considerably more ancient or evolutionarily distinct than previously suspected (reviewed by Convey et al. 2008), highlighting an often unappreciated but important element of biodiversity - that of local evolutionary intraspecific differentiation (see Chown \& Convey 2007). The highly fragmented and isolated nature of Antarctic terrestrial ecosystems provides an ideal environment in which differentiation can occur. Therefore, these ecosystems are clearly vulnerable to the inadvertent transfer of native biota from one part of Antarctica to a different region where they are alien. The risks are further inflated as it is nearly always the case that any such biota transferred are likely already to be well adapted to the environmental challenges of their introduction site.

Even within distinct Antarctic regions, analogous risks exist, as there are examples of isolated terrestrial communities lacking elements otherwise ubiquitous for that region. For instance, Convey et al. (2000b) identified that terrestrial ecosystems of isolated nunataks on the northern coast of maritime Antarctic Charcot Island lack any representatives of the Collembola, a group known from every other community examined in the maritime Antarctic. This lack of an otherwise ubiquitous biological and functional group provides an almost unique research opportunity to address fundamental questions in ecological theory relating to species and functional redundancy and the control of ecosystem structure. Any human contact with the ecosystems of Charcot Island, inevitably originating from a maritime Antarctic location where Collembola are native, creates a serious risk of the transfer of these arthropods. In recognition of this risk, the ice free regions of Charcot Island have recently been proposed and accepted as a new Antarctic Specially Protected Area (ASPA), imposing stringent entry requirements on any researchers proposing to visit this location (ATS 2008b).

A second and final example relates to the exceptional inland terrestrial ecosystems of Ellsworth Land, southern
Palmer Land, at the base of the Antarctic Peninsula) (Convey \& McInnes 2005). These ecosystems are currently unique worldwide in being dominated by Tardigrada and lacking any representatives of the Nematoda, a group previously thought to be ubiquitous in faunal communities (Freckman \& Virginia 1997). These ecosystems face at least two serious risks. First, as above, they lack many of the major taxonomic groups that are generally common in most other Antarctic terrestrial ecosystems, hence the probability of inadvertent transfer of pre-adapted Antarctic biota is again magnified. Second, this region hosts "forward support" facilities and field camps supporting, primarily, operations of the British Antarctic Survey (Sky Hi Nunataks) and tourism activities of Antarctic Logistics and Expeditions (Patriot Hills), as well as being visited by the aircraft and staff of other national operators. Lying south of the biogeographical boundary formed by the Gressitt Line, this region is clearly at enhanced risk of intracontinental transfer of species native only to one part of the Antarctic continent.

\section{Marine non-indigenous species}

The potential for introduction of alien marine taxa to the Antarctic region has been recognized in recent years (Frenot et al. 2005, Lewis et al. 2005, 2006), but has largely not formed a subject of study to date. Accordingly, very few data or records of occurrence are available. The non-indigenous green alga Enteromorpha intestinalis (Linn.) is well established in the intertidal zone at Half Moon Island in the South Shetland Islands, possibly introduced via the hulls of visiting vessels (Clayton et al. 1997). Lewis et al. (2003) investigated the possibility of transport of non-indigenous marine biota between Tasmania, Macquarie Island and the Antarctic continent by national operator and tourist ships, identifying three pathways relating to the transport of i) planktonic organisms from the Southern Ocean and Tasmanian waters, ii) epibenthic organisms from Tasmania, and iii) fouling assemblages. Lee \& Chown (2007) and Lewis et al. (2005) report instances of transport of marine biota into the Antarctic. Both anthropogenic and natural marine debris provide a vehicle for the transport of adhering biota into the Antarctic region (see Barnes et al. 2006), and may also have a direct and negative impact on indigenous biota through ingestion or entanglement. While this risk would appear to apply primarily to the marine biota, many coastal sites in the sub- and maritime Antarctic have been documented to accumulate substantial quantities of marine debris annually (Gregory \& Ryan 1997), including some that have been polluted before any human has set foot on them (Convey et al. 2002). This, thereby, extends the risk of introduction to include intertidal, supralittoral and even terrestrial biota capable of surviving exposure to the marine 
environment during transfer. Again, while the potential of these routes have been identified, no instances of establishment of non-indigenous biota through its utilization have been identified. Somewhat inaccurate publicity has been accorded to the recent record of a potentially invasive North Atlantic spider crab species being recorded from a trawl off the Antarctic Peninsula (Tavares \& de Melo 2004) and the potential for deep sea crabs to invade from lower latitudes in the Southern Ocean (Thatje et al. 2005). However, the former relates to a single record, with no subsequent records or evidence of establishment, while the latter relates to potential distributional shifts rather than actual evidence of anthropogenically mediated invasion.

\section{Fisheries}

The history of the exploitation, management and protection of Antarctic marine resources follows the same pattern as that of marine systems in the rest of the world. Exploitation of fur seals, penguins, whales and finfish in the Southern Ocean have all followed the stages of exploration, exploitation, over-exploitation, followed by management (e.g. Kock 1992, Myers \& Worm 2003, Pauly \& Palomares 2005). Over-exploitation led to the decimation, and local extinction in some localities, of populations of Antarctic fur seals (Arctocephalus gazella (Peters)), southern elephant seals (Mirounga leonina Linn.), and king penguins, as well as severe depression of marbled rockcod (Notothenia rossii Richardson), mackerel icefish (Champsocephalus gunnari Lönnberg) and the great whales (Kock 1992, Croxall \& Nicol 2004, Ballance et al. 2006). Following the outlawing of take and the initiation of management, with complete cessation of take for some species, king penguins, fur seals and elephant seals recovered completely (e.g. Rounsevell \& Copson 1982, Laws 1994, SCAR 2006b) while whales and fish have shown little evidence of recovery (e.g. Kock 1992, Baker $\&$ Clapham 2002, Barrera-Oro \& Marschoff 2007). Some populations of elephant seal have since declined, probably owing to prey depletion (Ainley \& Blight 2008), while others have remained stable or increasing. Since 1982, the exploitation and regulation of Antarctic marine living resources has been assigned to CCAMLR. As noted earlier, CCAMLR was created under the scope of the Antarctic Treaty System and applies to the Southern Ocean south of the Antarctic Polar Front. It has attempted to practise more than a single-species approach to fishery management: an ecosystem approach with extensive use of the precautionary principle, which has been a paradigmatic example for Regional Fisheries Management Organizations (RFMOs; Constable 2001, Croxall \& Nicol 2004). Over the past decade, scientific research has provided some information on the current status of fish stocks that had been exploited pre-CCAMLR. It has also provided

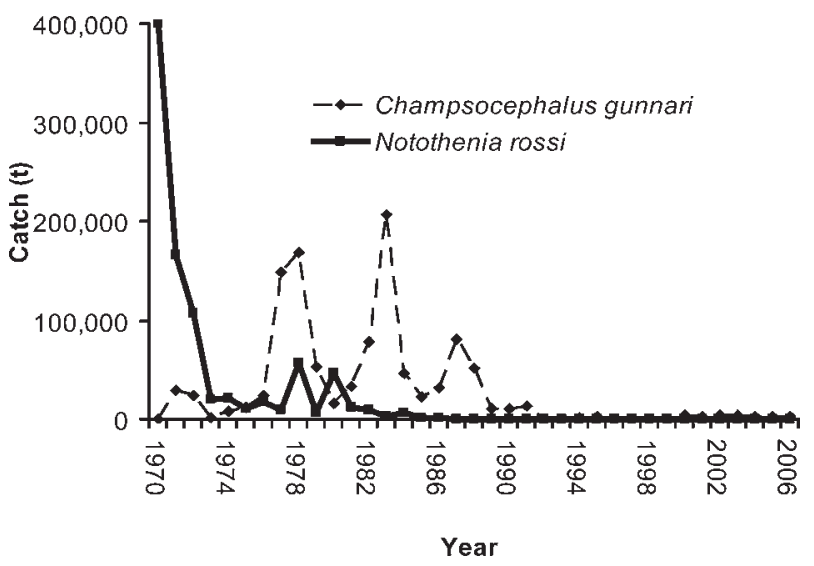

Fig. 4. Catch statistics for the marbled rock cod (Notothenia rossii) and mackerel icefish (Champsocephalus gunnari), in the statistical area 48 (South Georgia and Antarctic Peninsula). (Data from CCAMLR database)

information to assist with the management of the two main active fisheries for the deep sea toothfish (Dissostichus eleginoides Smitt, D. mawsoni Norman) and the crustacean Antarctic krill, along with a third, much smaller fishery for mackerel icefish in the Scotia Sea. The impacts of fisheries on non-target species and the marine ecosystem in general are poorly understood (see recent reviews in Ballance et al. 2006, Ainley \& Blight 2008). One exception is the bycatch of seabirds during fishing operations, which has received a great deal of research, owing to severe decreases in the breeding populations of affected species, considerable public interest and pressure from conservation groups.

\section{Impacts on target populations}

Fish

Comprehensive summaries and detailed reviews of the first 15-20 years of finfishing in the Southern Ocean are available (e.g. Gon \& Heemstra 1990, Kock 1992, Agnew 2004, Duhamel et al. 2005, Kock et al. 2007). Finfishing in the Southern Ocean began in 1961 with the operation of Soviet distant-water fleets in the south-west Atlantic and then spread rapidly into the Scotia Sea. The fishery in this sector began on the marbled rockcod at South Georgia. The stock was depleted within two seasons after about 500 000 tonnes was taken (CCAMLR 1990). After some years of low fishing effort, the fishery switched to the mackerel icefish (Fig. 4). It is possible to conclude that the Soviet fleet significantly reduced rockcod and icefish stocks at South Georgia over three years before moving to the Antarctic Peninsula area (around Elephant Island and the South Shetland Islands) and the Kerguelen Plateau, where, again, the stocks of the same species were overexploited (Kock 1992). Other fish stocks that declined substantially after only a few years of fishing were the green notothenia 


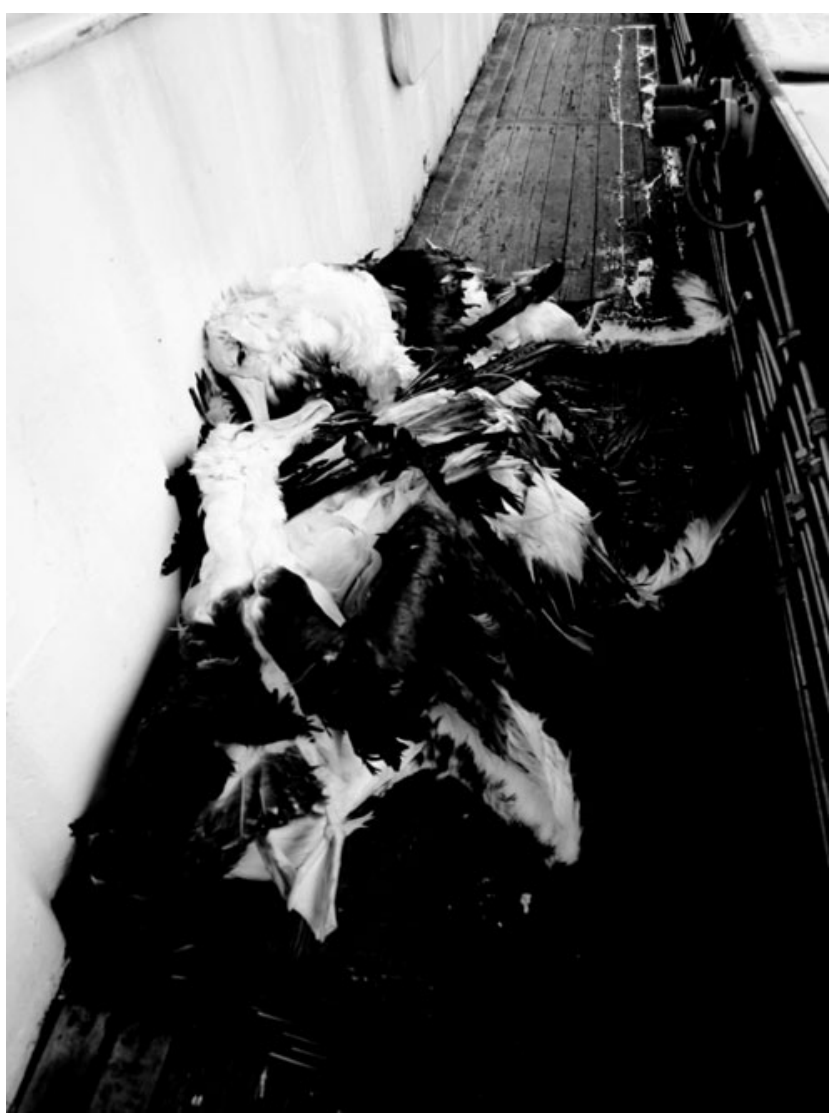

Fig. 5. Black browed albatross killed in an Antarctic longline fishery. (Photo by Carlos Moreno)

(Gobionotothen gibberifrons (Lönnberg)), the Scotia Sea icefish (Chaenocephalus aceratus (Lönnberg)) and the South Georgia icefish (Pseudochaenichtys georgianus Norman; Gon \& Heemstra 1990, Kock 1992).

In total, 12 species of finfish have been commercially fished in the Southern Ocean. Data on stock estimates are not available for all species or for all locations and, indeed, very little information exists on the pre-exploitation biomass of the exploited species. Published studies continue to demonstrate little recovery of many of the stocks that were exploited before the creation of CCAMLR. For example, Kock et al. (2004) reported that no substantial recovery of the marbled rockcod has been observed at South Georgia and off Elephant Island, more than two decades after the closure of the fishery. Further, no recovery of the stocks of marbled rockcod or humped rockcod (Gobionotothen gibberifrons) has been observed in the particularly well-researched coastal zones of the South Shetland Islands (Barrera-Oro \& Marshoff 2007). Barrera-Oro \& Marshoff (2007) concluded that "despite an overall increasing trend of $N$. rossii (marbled rockcod) catches from 1991 to 2006, the current level was half of that found in the early 1980s (before the fishery), while those of G. gibberifrons (humped rockcod) had further
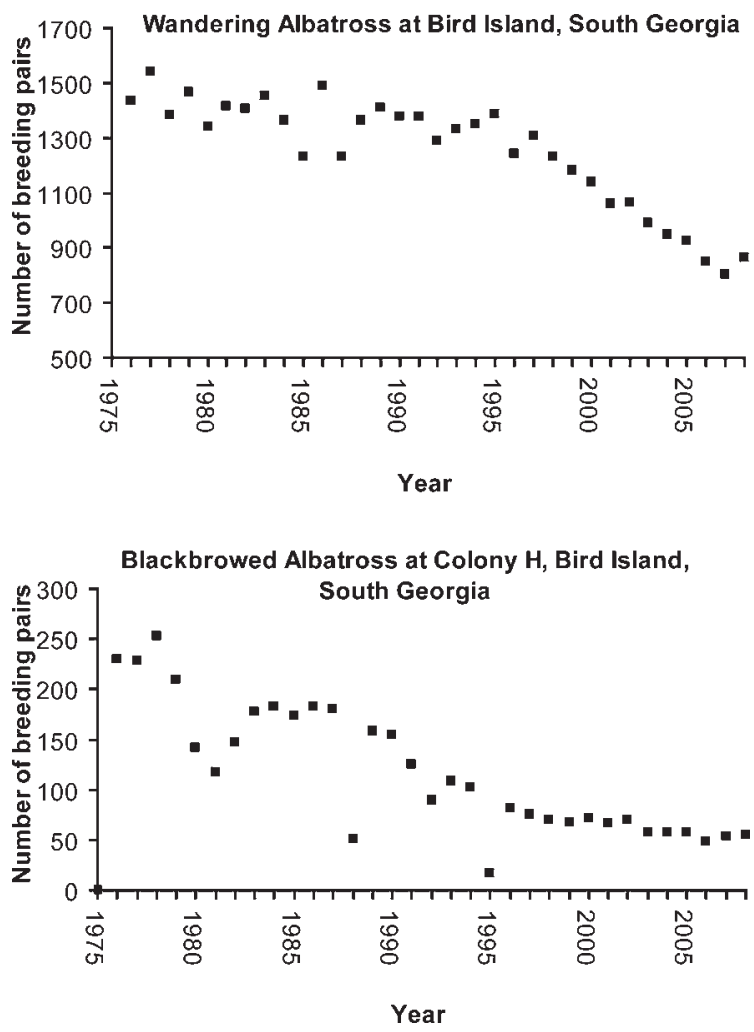

Fig. 6. Numbers of pairs of breeding albatrosses in study colonies at South Georgia, south of the Antarctic circumpolar front (unpublished data, courtesy of the British Antarctic Survey).

declined and remained close to zero". Despite the fact that surviving individuals of the species have increased in size, they have been unable to reproduce to rebuild the populations, resulting in exceedingly low fish populations. Ainley \& Blight (2008) have hypothesized that a climate oscillation may be responsible for lack of recovery. In the vicinity of Elephant Island, trawl surveys showed that 30 years of fisheries have had considerable impacts on the stocks of mackerel icefish, marbled rockcod, blackfin icefish (Chaenocephalus aceratus) and humped rockcod (Kock 1998). Jones et al. (2000) concluded that overall levels of biomass around the South Orkney Islands are so low that most fish stocks are probably not in a state that could withstand even limited exploitation.

The fishery for the deep sea species Patagonian toothfish (Dissostichus eleginoides) began in the late 1970s in South Georgian waters and the Scotia Arc, though the degree to which it was fished prior to record keeping is unknown (Kock 1992). This was the first fishery that CCAMLR had the opportunity to manage, other than by closure. The Scientific Committee of CCAMLR, in the absence of ecological data, has opted for what it believes to be a precautionary approach to this fishery. It introduced an international scheme of scientific observors, and a consensus agreement to establish a Total Allowable Catch 
(TAC) within small-scale management units. Due to its high commercial value, the toothfish fishery has suffered continuing and pervasive threats from illegal, unreported and unregulated (IUU) fishing, with IUU contributing significantly to the total global catch of toothfish (Agnew et al. 2008). By the early 2000s, the total IUU catch for toothfish was estimated to be at least double the legal one, well in excess of the aggregate global limit recommended for the regulated fisheries for all CCAMLR waters. Some evidence indicates that IUU activities are under control in areas subject to national jurisdiction, e.g. Kerguelen Shelf, South Georgian Shelf (Croxall \& Nicol 2004), but may be intensifying in others, especially over high-sea and oceanic banks. This is particularly true in the Indian Ocean sector where extensive exploitation of large adult toothfish by IUU vessels could have already caused substantial, longterm damage to the stock (CCAMLR 2007). Over the years, the toothfish fishery has expanded farther south and included a second species, the Antarctic toothfish (D. mawsoni). The fishery has now reached as far as it possibly can, to the Antarctic's southernmost shores, those of the Ross Sea.

\section{Krill}

The Antarctic krill fishery, in terms of tonnage, has been the largest fishery in the Southern Ocean since the late 1970s. The fishery is the largest one for a crustacean anywhere in the world and has prospects for becoming the largest global fishery, especially as stocks of clupeid species decline elsewhere (Nicol \& Endo 1997, Croxall \& Nicol 2004). The Antarctic krill is a major component of the diet of a variety of species, that may rely increasingly on krill as finfish stocks diminish as a result of fishing activities (Alonzo et al. 2003, Ainley \& Blight 2008). The krill fishery currently occurs in certain locations around South Georgia, the South Orkney Islands and the Antarctic Peninsula, and is in total spatial overlap with the foraging ranges of krill-dependent predators such as penguins and seals (species included in the CEMP, CCAMLR Ecosystem Monitoring Program). Excessive localized fishing effort may result in significant impacts on species that depend on krill for food, particularly during the breeding season. Up to the present, the Antarctic krill fishery has remained well below CCAMLR-established total catch limits, with c. 120000 tonnes being caught each year during recent seasons. However, future development of products for aquaculture, pharmaceutics and medicine is likely to drive growth in the krill fishing industry (Nicol \& Foster 2003). New technology, such as the continuous pumping of krill, is becoming more widely deployed, in spite of the lack of reliable catch and effort data and understanding of its impacts on larval and juvenile fish (CCAMLR 2007), or on CEMP species, assuming elevated take levels.

\section{Incidental mortality and bycatch}

Seabirds

Longline fishing operations for toothfish began under CCAMLR supervision in 1986. It quickly became clear that this fishery carried considerable risk of fatality for seabirds like albatrosses and petrels, which are scavengers and thus readily feed on longline baits, get hooked and drown (Fig. 5). Decreases in albatross populations on the sub-Antarctic islands became evident in the mid-1990s, particularly at South Georgia and Iles Crozet where the longest series of annual population counts were available (Fig. 6; Croxall et al. 1998, Jouventin \& Weimerskirch 1990). Observations and census data linked population decline to incidental mortality associated with longline fisheries (Croxall et al. 2007). Delord et al. (2005) reported that 26668 seabirds were killed between 2001 and 2003 by legal toothfish longline fishery boats operating around the Iles Kerguelen and Iles Crozet. Species included (in decreasing order by number caught) white-chinned petrel (Procellaria aequinoctialis Linn.), grey petrel (Procellaria cinerea Gmelin), giant petrels (Macronectes sp.), blackbrowed albatross (Diomedea melanophrys Temminck) and grey-headed albatross (D. chrysostoma Forster). The highest mortality of white-chinned petrels, grey petrels, black-browed albatrosses and grey-headed albatrosses occurred during the chick-rearing period. Longline vessels using automatic baited lines caught many more birds than those using manually baited lines (Delord et al. 2005). Mortality levels from the longline fisheries in CCAMLR waters were unsustainable for the albatross populations involved (CCAMLR 2002). These long-lived birds delay breeding until ten years old, do not necessarily breed every year, and only produce one fledgling at best when successful. They are thus highly susceptible to adult mortality. In view of the mortality rates from longline fisheries their decline could be potentially irreversible within two or three decades (Croxall \& Nicol 2004).

IUU fishing has compounded the problem. The CCAMLR Scientific Committee estimated that the number of seabirds killed in IUU fishing alone could have ranged between 151000 and 543000 during the ten years between 1996 and 2006 (CCAMLR 2007b). Around the Prince Edward Islands, as is true elsewhere, seabird mortalities from legal and IUU longline fishing have led to significant impacts on the breeding populations of several species of seabirds (Nel et al. 2002).

\section{Other species}

Apart from seabirds, industrial fishing operations also directly affect other non-target species, including seals and fish, as well as benthic communities. Juvenile fish and fish larvae are often caught as bycatch during commercial fishing for Antarctic krill (Moreno 1995, Croxall \& Nicol 2004). Fur seals may become caught in the nets of krill 
fishers (CCAMLR 2003). Some cetaceans, such as sperm whales (Physeter macrocephalus) can become entangled in the line and this has occasionally resulted in mortality (Kock et al. 2006). During longline toothfish fishing operations, many grenadiers, skates and rays - up to $20 \%$ of the catch - are taken and discarded (CCAMLR 2003). CCAMLR has adopted interim bycatch limits for some of these taxa, together with rules requiring fishing activities to move a specified distance once a threshold level of skate and ray bycatch has been reached (CCAMLR 2003, Kock et al. 2007). Little effort has been made as of yet to quantify damage of longline anchors and hooks to benthic invertebrate communities.

\section{Mitigation efforts}

Starting in 1992, CCAMLR took the lead in addressing the problem of incidental mortality in fisheries in order to mitigate incidental take. International scientific observers were put on board vessels not only to sample fish, but also to collect reliable information about the ecological interactions with non-target species (including seabirds, other fishes and marine mammals) during fishing operations. One of the most important measures with regard to seabirds around South Georgia was to change the fishing season from summer to winter, as birds do not remain close to their nesting colonies during winter. Other measures used by CCAMLR to minimize incidental mortality of seabirds associated with longline fishing, include the use of streamer lines or "Tori poles" to keep birds away from sinking longlines, banning offal discharge to avoid attracting birds, increased weighting regimes for faster sink rates to ensure that lines sink before birds detect them, and night setting (Croxall \& Nicol 2004). Seabird bycatch from legal longline fisheries in CCAMLRmanaged waters became essentially negligible from 2002 onwards (Croxall \& Nicol 2004) (Fig. 4). However, numbers of bird deaths outside of CCAMLR waters are still high for several reasons. Firstly, IUU vessels do not employ the mitigation measures that reduce large numbers of incidental mortalities. Secondly, Antarctic seabirds like albatrosses and petrels move to warmer waters during inter-nesting periods, where CCAMLR-type measures have yet to be invoked. In the South Atlantic, the impacts of pelagic fisheries off the coast of Brazil, Uruguay, Argentina and Africa are an important conservation issue for many seasonal Antarctic species, including the southern giant petrel, grey-headed albatross and wandering albatross (e.g. Poncet et al. 2006, Bugoni et al. 2007, Seco-Pon et al. 2007).

\section{Impacts on marine ecosystems}

Antarctic marine systems have suffered major perturbation through hunting and fishing over the last two centuries and the consequential changes in these ecosystems (see reviews in Ballance et al. 2006, Ainley \& Blight 2008) have lost attention in current research (Ainley et al. 2007, see also Nicol et al. 2007). The prevailing theory of the 1980 s, the so-called "krill surplus" hypothesis, postulated that near extermination of large whales in the 20th century led to a surplus of krill as a key prey in the Southern Ocean ecosystem, with consequent increases in the numbers of other krill consumers (Ballance et al. 2006). While some studies have found evidence that supports this hypothesis, others argue that the loss of whales alone is not adequate to explain the population trends of some supposed key krill-eating species (e.g. gentoo, Adélie and macaroni penguin (Eudyptes chrysolophus Brandt); see Emslie \& Patterson 2007, Ainley \& Blight 2008, McClintock et al. 2008).

The impacts of fisheries on Antarctic marine ecosystems are poorly understood. An analysis by Ainley \& Blight (2008) indicates that removal of demersal finfish from insular and northern continental shelves during the 1960s1980s had significant effects on populations of fish-eating predators, such as gentoo and macaroni penguins, Antarctic fur seals (Arctocephalus gazella Peters), southern elephant seals, and Antarctic shags (Phalacrocorax bransfieldensis Murphy; see also Barrera-Oro et al. 2007). The removal of finfish means that some of its predators may suffer food scarcity, some of its prey, such as salps (e.g. Salpa thompsoni (Foxton)), will experience less predation and in addition climate effects will become more prominent (e.g. Osterblöm et al. 2007). This introduces the possibility of trophic cascades rippling through foodwebs at the community level, with changes in the medium-term biodiversity and relative abundance of other species in the demersal community (Worm et al. 2006). For example, preliminary information collected in waters off Ross Island indicates that fish-eating killer whales have become less frequent and Adélie penguins have begun to feed on silverfish (toothfish prey) to a greater degree during chick feeding since the advent of the toothfish fishery (DeVries et al. 2008). These first-order ecological effects in the Ross Sea remain under study but the potential for trophic cascades is high (Ainley et al. 2007) in accordance with scenarios played out in other parts of the world's oceans with the removal of top predators, of which the toothfish is one (Pauly \& Maclean 2003, Osterblöm et al. 2006, Daskalov et al. 2007). Furthermore, the destruction that bottom trawling and longline gear can cause to benthic communities has become a topic of concern in the Southern Ocean as elsewhere in the world's oceans (CCAMLR 2007, Kock et al. 2007). There is sufficient evidence globally that benthic habitats comprising slowgrowing, habitat-forming, sessile species, such as deep sea corals and sponge communities could take much longer than three decades to recover from significant fisheries disturbances. However, little information exists on the 
extent to which damage might have already occurred in the Southern Ocean (CCAMLR 2007).

\section{Discussion}

Over the past decade, environmental management of Antarctica and the Southern Ocean has taken place under the framework of the Environmental Protocol to the Antarctic Treaty and the Convention for the Conservation of Antarctic Marine Living Resources (CCAMLR). In this section, we examine how information provided by research on human impacts can be fed back to inform decisions within these environmental management regimes and discuss what is needed to improve the feedback mechanism between science on human impacts and the management and minimization of these impacts.

\section{Fisheries}

CCAMLR was established, as noted above, to manage the impacts arising from the exploitation of marine resources in the Southern Ocean. Its charter has directed it to be a trailblazer in its field, attempting to manage at the ecosystem level and use precautionary approaches, and while much remains to be tested in terms of its overall effectiveness, it has brought many positive results in spite of continuing challenges. In terms of addressing impacts of fisheries on target populations, it has developed what are thought to be precautionary approaches to Total Allowable Catches (TACs) and specific policies to manage new and exploratory fisheries (Willock \& Lack 2006). On the other hand, other than in local and national areas, it has not been able to effectively control IUU fishing, which probably exceeds the levels of permitted fishing over wide areas (Croxall \& Nicol 2004). In order to address bycatch and ecosystem impacts, CCAMLR has put in place effective seabird and seal bycatch mitigation rules and other gear restrictions. Its Scheme of International Observation collects data on bycatch onboard fishing vessels, although it is not always widely used (CCAMLR 2005). The CEMP was established to monitor the effects of the krill fishery on the ecosystem by assessing change in the natural history parameters of krill predators. Data are being systematically gathered from a network of specific sites on selected species. How these data will be used in the decisionmaking process to establish and monitor TACs, however, has yet to be seen (Constable 2004, Kock et al. 2007).

CCAMLR's approach has so far focussed mainly on the krill fishery and predators either directly or indirectly dependent on krill (Kock et al. 2007). Finfisheries, such as toothfish and mackerel icefish, which are currently managed in a single-species context, are not included in the CEMP or any other similar monitoring programme, although CCAMLR believes that its precautionary approach to TACs take these species' needs into consideration. Little account, as of yet, has been taken of the responses of predators or other elements of the ecosystem to proposed harvest strategies (Constable 2004, Kock et al. 2007). Special consideration will need to be given to ensure that harvesting will not affect predators in unforeseen and sometimes indirect ways, in particular those for which CCAMLR is unable to monitor effectively, such as whales, pack ice seals, many seabirds, fish and squid (Constable 2002). Marine protected areas, area-based management rules and closures can provide needed protection to ecosystems from the impacts of fisheries. Bottom trawling is prohibited throughout large parts of the CCAMLR area, providing protection to sensitive benthic habitats. Little consideration has yet been given to the effects of longline fishing on the benthic communities of invertebrates. Finally, while it is within its primary responsibility and expertise to designate marine protected areas, a management tool shown to be effective elsewhere, CCAMLR has, to date, taken very little direct action (CCAMLR Performance Review Panel 2008).

\section{Protection of native flora and fauna}

Protection of the native flora and fauna of Antarctica is one of the key environmental principles laid down in the Environmental Protocol and is elaborated in more detail under Annex II to the Protocol, Conservation of Antarctic Fauna and Flora. Since the entry into force of the Environmental Protocol, the deliberate introduction of nonindigenous species to Antarctica has largely been stopped. Measures have been introduced to minimize the disturbance caused by mechanized and foot traffic, such as the production of guidelines for the operation of aircraft near concentrations of birds and site guidelines for visitors. Taking and handling of animals is now regulated through a strict permit system and is only allowed for research purposes. While measures are enforced by individual national programs, SCAR is in the process of updating its code of conduct for the use of animals for scientific purposes in Antarctica, with the goal of bringing this activity in line with good practice elsewhere. A protocol is being developed to minimize the environmental disturbance of human activities within Antarctic Specially Protected Areas (NSF/COMNAP/SCAR 2005) whilst SCAR has recently agreed a new code of conduct for Antarctic field science.

In order to meet the challenges posed by the increasing diversification and intensification of human activities in Antarctica, additional measures to protect native flora and fauna of Antarctica will be needed. One such case is the management of the risks of the introduction of nonindigenous species. The current level of knowledge on non-indigenous species in Antarctica is clearly based on a very incomplete dataset, with relevant information simply not available for many biological groups (in particular, but 
not restricted to, microbial groups) and geographical locations, or over the extended timescales required to confirm establishment and population trends. Long-term data are essential for the establishment of appropriate risk management protocols, in identifying new instances of introduction, monitoring the status of species already established and assessing the effectiveness of any mitigation measures adopted. Through the relatively limited number (in absolute terms) of access routes, vessels and journeys to Antarctica, it is amongst the most practicable of continents on which to apply control measures to minimize this risk, in order to maintain its unique terrestrial and marine ecosystems. Possible measures include stringent procedures to ensure rodent-free status of ships and aircraft, logistical planning to minimize the risk of intra-regional and local transfer of propagules to pristine locations, control of visitor numbers and access to more sensitive or pristine sites, and cleaning/sterilization of high risk transport locations for aliens, such as cargo surfaces, foodstuffs and clothing (important in both inter- and intraregional contexts) (e.g. Whinam et al. 2004, Frenot et al. 2005, De Poorter et al. 2006).

The rapid increase in tourism is another case which poses challenges to the protection of native flora and fauna and to the general environmental management of Antarctica. In the last ten years, the numbers of tourists visiting and landing in the Antarctic region has increased by over threefold (IAATO 2008). For many years, tourists arrived on small ships carrying 50-120 passengers and were taken ashore daily in inflatable craft with outboard engines. Since 1990, larger cruise ships that could carry up to 500 passengers, and from 2000 onwards, liners that could carry 800-3000 passengers (not landing ashore) entered the market (Bertram 2007). The monitoring, cumulative impact, and environmental impact assessment of tourism activities has become a concern and clearly, long-term studies are likely to be necessary to detect any possible cumulative impacts of ship-based tourism (Hofman \& Jatko 2000). Since 1994, researchers from the Antarctic Site Inventory have made repeat visits to sites along the Antarctic Peninsula that are most heavily visited by expedition tourists, and to sites which are most prone to potential environmental disturbance from human visitors (Naveen 2003). A large body of data has been collected, and the challenge ahead lies in identifying changes to a site's baseline reference state and, if possible, determining whether any detected changes are of naturally occurring or anthropogenic origin (Hofman \& Jatko 2000). Trathan et al. (in press) pointed out that it may never be possible to completely identify all of the many subtle influences that impact upon the breeding numbers of gentoo penguins on Goudier Island, one of the most frequently visited tourist sites in Antarctica. De Villiers (2008) further concluded that there is no "one size fits all" solution to managing human disturbance to wildlife in Antarctica. Not only are wildlife responses to human activity species-specific, activity-specific and location-specific, in many cases it remains unclear if less than minor or transitory impacts, e.g. from pedestrian visits, can accumulate into more harmful outcomes for wildlife over longer periods (Holmes et al. 2008). Long-term monitoring studies and targeted experimental studies are needed to provide information in detecting and managing potentially harmful human impacts on wildlife. At the same time, the precautionary approach should be applied with vigour with regard to the management and the regulation of tourist numbers and proximity to colonies, as advocated by many studies (e.g. Wheeler et al. 2008, Trathan et al. in press and references therein).

\section{Chemical and sewage contamination}

Chemical and sewage contamination are treated generally under the Environmental Protocol through its provisions for the protection of the Antarctic environment, air and water quality, and are dealt with more specifically under Annex III to the Environmental Protocol, Waste Disposal and Waste Management and Annex IV, Prevention of Marine Pollution. Since the entry into force of the Environmental Protocol, sewage treatment has become compulsory for research stations occupied by more than 30 people. All open burning of wastes has ceased. The introduction of pesticides, polychlorinated biphenyls (PCBs) and polystyrene packaging into the Antarctic Treaty area have been prohibited.

In the ten years since the entry into force of the Environmental Protocol, there has been relatively little progress in implementation of the provision requiring all past and present waste disposal sites on land and abandoned sites of Antarctic activities to be cleaned up by the generator(s) of such wastes and the user(s) of such sites (in Annex III). This requirement opens up a number of significant issues for managers of national programs, or other polluters, as it applies retrospectively to a large legacy of waste, perhaps including of the order 1-10 million $\mathrm{m}^{3}$ of contaminated soils and sediments (Snape et al. 2001b). Furthermore, it does not establish to what level sites should be cleaned-up, does not address liabilities, policing, penalties or a mechanism for recovery of damages, and does not specify what type of monitoring is required to demonstrate that any activity does not result in adverse environmental impacts.

Over the past decade, a number of countries have undertaken site clean-ups to remove waste dumps and disused infrastructure left over from past activities. Examples include the United Kingdom's removal of the waste dump site at Fossil Bluff and disused stations along the Peninsula, and the clean-up operations at Syowa (Japan) and Marambio (Argentina) stations as well as at ECARE (Uruguay) and the abandoned Cape Hallet station (New Zealand, USA). Most clean-ups 
have largely involved the bulk removal of surface rubbish while few have undertaken full remediation of contaminated soils and sediments (Crumrine 1992, Kohnen \& Lukin 1998, COMNAP 2007). The complete remediation of World Park Base by Greenpeace in the early 1990s (Roura 2004) and the partial clean-up at Casey Station in 2003-04 (Stark et al. 2006) are examples of the latter type of activity. One reason for the lack of implementation of the remediation provision is that no universally accepted standards exist, and neither is there any environmental protection authority insisting that sites be rehabilitated. Another reason is cost. Remediation costs are typically ten times greater than in temperate developed countries, and many low-cost technologies, such as bioremediation, are yet to be proven in Antarctica. However, when Annex VI to the Environmental Protocol, Liability Arising from Environmental Emergencies, enters into force all Antarctic operators will have the legal responsibility for the clean up or the cost of the clean up after any accidental event that leads to significant and harmful impact to the Antarctic environment. Signed in 2005 and still to be ratified by all ATCPs, Annex VI could possibly force the issue of remediation to be considered in earnest.

\section{Filling the gaps in science-based environmental management}

Through the work of the Scientific Committee to CCAMLR, SCAR and the Committee on Environmental Protection to the Antarctic Treaty Parties, science-based environmental management has become part of the core of the ATS. As demonstrated in this review, research on human impacts can be used to inform environmental management decisions which can, in turn, enhance the minimization and mitigation of these impacts, forming a feedback mechanism. Gaps, however, still exist in this process. If aspects can be fulfilled, the robustness of science-based environmental management in Antarctica will be effectively enhanced.

Most of the research on the impacts of human activities on the Antarctic environment is focussed on relatively small areas and in single disciplines. Human impacts on a regional or continental scale are rarely examined, making it difficult to have an overview of the scale of human impacts or to be able to provide information on the effectiveness of multi-disciplinary management regimes, such as environmental impact assessments (EIAs). The requirement for an EIA for every activity prior to its commencement is one of the most important elements of the Environmental Protocol. Under Annex I to the Protocol, Environmental Impact Assessment, three levels of assessments are defined Preliminary Assessment (PA), Initial Environmental Evaluation (IEE) and Comprehensive Environmental Evaluation (CEE) - to be applied to activities with different probable levels of impacts. In the assessment, the impacts of the proposed activity are predicted and assessed, and this information is used to inform the decision as to whether a proposed activity should proceed, and if so, whether in its original or modified form. Clearly, the effectiveness and credibility of the EIA process has a significant bearing on the magnitude and extent of the environmental impacts that are the subject of the present paper. A number of studies have highlighted concerns with the implementation of the EIA provisions: impacts predicted in the EIAs are seldom followed up and verified, EIAs only apply to individual activities, and do not address risks caused by the sum of operations, and the multiple facets of tourism are not addressed fully in IEEs and have not been addressed in any CEEs (Kriwoken \& Rootes 2000, Hemmings \& Roura 2003, Bastmeijer \& Roura 2007). Current research on human impacts rarely provides the information required to assess and verify environmental impacts predicted in EIAs. Consequently no data can be fed back to assess the effectiveness of EIA provisions. As the sole gatekeeper of whether an activity can or cannot go ahead in Antarctica, the EIA process needs to be informed and tuned by more robust checks and balances, especially in view of the expansion of both national and commercial activities in Antarctica.

Environmental monitoring is seen as integral to the EIA process (NSF/COMNAP/SCAR 2005) under Annex 1 of the Environmental Protocol, and is considered as an important activity within the Protocol for assessing, understanding and managing human impacts in Antarctica. However, this effort, which is crucial to the verification of predicted impacts and the early detection of unforeseen effects of activities, has been under-deployed. Despite some monitoring initiatives by individual nations and groups of nations, there is still an overriding need for overall coordination of monitoring activities in Antarctica. A small number of baseline studies have been set up in vegetation communities around Antarctic stations with the intent of providing monitoring data for future changes (Thor 1997 and references therein, Hee et al. 2007). Coordinated and effective monitoring programs of impacts on vegetation and ecosystems more widely are still needed (ASOC 2004, Frenot et al. 2005, 2007). The Long Term Ecological Research (LTER) programmes set up in the McMurdo Dry Valleys and off Anvers Island are exemplary in gathering process and baseline data on the biota in order to serve as a context for any observed changes. Few sewage outfalls have a comprehensive monitoring program in place despite research showing that sewage released from both large and small research stations may have significant cumulative environmental impacts. Given that there are 53 active Antarctic stations (with some form of treatment attempted by around 50\%), surprisingly few studies investigating the extent of sewage impacts are publicly available (Gröndahl et al. 2008). Long-term monitoring data is essential for informing future decisions on 1) appropriate types and degrees of sewage 
treatment, 2) the design and siting of outfalls, and 3) likely impacts of sewage disposal on Antarctic wildlife. Similarly, long-term studies and targeted research are needed to provide information on which to base tourist management decisions.

Not all human impacts have been studied extensively, as is clear from the preceding discussion, severely hindering wellinformed, science-based environmental management. The impacts of acoustics on marine mammals in the Southern Ocean is one such example where SCAR (2006a) has repeatedly highlighted the need of targeted research in order to provide a sound scientific basis to underpin any future management of ocean noise. Even less attention has been paid to the impacts of human activities on the intrinsic, wilderness and aesthetic values of Antarctica values which are afforded protection under Article 3 of the Environmental Protocol. Again, the lack of research does not necessarily reflect a lack of impacts. An individual human activity may have a relatively small direct impact on the wilderness values of the immediate surroundings but, if it takes place far from existing centres of activity and where there have not yet been impacts by human activities, it will break up the integrity of the wilderness area and fragment it into smaller pieces, thereby significantly eroding the key characteristics that make this wilderness area unique. According to Keys (1999), the area of wilderness in Antarctica is being diminished as a result of increased accessibility to and within Antarctica, continued growth in numbers and size of stations, field camps and depots, rapid increase in numbers of tourists, expansion of fisheries and increased commercialization of Antarctica. Summerson \& Riddle (2000) state that Antarctic wilderness is being modified through activities or relics of former activities that can be readily sensed by humans such as by sight or sound, as well as those that cannot be readily sensed, such as the area impacted by an oil spill, areas where radioactive isotopes have been used for biological research, and dust plumes. According to Hemmings (1997), aesthetic and wilderness values may be impacted at differing scales, from the localized to the circumpolar. Apart from these general appraisals, little work has focussed on the consideration, monitoring, minimization or the management of impacts of human activities on Antarctica's wilderness and aesthetic values (Bastmeijer \& Roura 2007). Globally, wilderness protection is not a novel concept; wilderness laws and policies exist in 15 countries in both northern and southern hemispheres (Kormos 2008). They provide real-life examples of protection of wilderness values, although their relevance to the Antarctic context still needs to be examined. Compared to the other human impacts that have been discussed in this review, it is evident that a lot more work is still needed in order to adequately understand, mainstream and implement the protection of Antarctica's wilderness and aesthetic values.
While there will always be an imperative for additional science and information on which to base decisions, uncertainty is a basic and largely unavoidable aspect of environmental management in Antarctica. The precautionary approach, which CCAMLR and other international environmental regimes have explicitly adopted and implemented to varying degrees, appears to be highly appropriate in the context of the environmental management of Antarctica. It promotes the anticipation, prevention and mitigation of threats to the environment. Complete certainty regarding an environmental harm should not be a prerequisite for taking action to avert it, and risks associated with unsustainable practices in conditions of uncertainty are thereby minimized (Cooney \& Dickson 2005). The aim of the precautionary approach is to ensure that uncertainties about the impacts of an activity are weighed in the decisionmaking process. Bastmeijer \& Roura (2004) highlighted some of the practical measures implied by application of the precautionary principle to Antarctic tourism. These include: improving the applicability of EIA to tourism, improving the process of assessment of cumulative impacts prior to the activity rather than expecting that monitoring during and after the activity has taken place will provide all the answers, adopting restrictions on the permissible types of activities, and establishing temporal or spatial limitations for certain sites as required by their specific values and characteristics. Indeed, most of these and other measures would also be relevant where the precautionary approach is applied to environmental management in Antarctica and the Southern Ocean. As a unique global commons, Antarctica, the Southern Ocean and its environment continue to deserve the highest level of protection. The environmental management regimes of the Antarctic Treaty System have often been lauded as being innovative and forward-looking, setting the example for other parts of the world. In the $21 \mathrm{st}$ century, it is necessary for these regimes to continue to evolve and deliver bold and forward-looking solutions to the new environmental challenges facing the Antarctic region.

\section{Conclusions}

Bargagli (2005) concluded that "although scientific research in Antarctica is of paramount importance in addressing climatic and environmental challenges, there is no doubt that the value of Antarctica for science should be weighed against the environmental impact of scientific work and its logistic support." We contend that this philosophical approach should be applied to all human activities in Antarctica, regardless of the nature of the activity. Any human visit carries with it a risk of ecosystem disturbance and of the introduction of new non-indigenous species. The survival of any human necessitates the use of fuels and construction materials, the production of wastes and interactions with flora and fauna. Increased use of renewable energy, optimization of logistics, removal of wastes, etc., 
certainly contribute towards reducing the impacts of human activities in the Antarctic and the Southern Ocean. Yet, exploitation of marine resources, construction of infrastructure, increased marine and air traffic and possible accidents and leaks undoubtedly leave imprints on the Antarctic environment. Unfortunately, Antarctica can no longer be considered pristine, many impacts from human activities are neither minor nor transitory, and some are irreversible. Over the past decade, CCAMLR and the Environmental Protocol have succeeded in reducing some environmental impacts of human activities on the Antarctic environment. In the coming decades, the effectiveness of these regimes will be put to the test, in the face of the continuing increase in intensity and diversity of human activities in Antarctica. Outside Antarctica, global influences, such as climate change and long-distance pollution may act synergistically with local impacts, making management even more difficult. Environmental monitoring and targeted research are urgently needed to inform management decisions. At the same time, environmental management need not be paralysed by the lack of data and should instead, fully embrace the precautionary approach and deliver bold and forward-thinking solutions to the environmental challenges facing Antarctica in the 21st century. The preservation of the Antarctic environment, including its unique intrinsic, wilderness and scientific values is a fundamental principle of the Antarctic Treaty, and to fail to do so at this juncture would be an indictment of the Antarctic community.

\section{Acknowledgements}

The authors would like to thank Mark Belchier, Roberto Bargagli, Yan Ropert-Coudert, Marienne de Villiers, Virginia Gascon, Katja Heinke, Alan Hemmings, Nick Holmes, Hans-Ulrich Peter, Richard Philips, Ricardo Roura, Rupert Summerson, Claire Waluda, Barry Weeber, Rodolfo Werner Kinkelin, the librarians at the Scott Polar Research Institute, David Walton and three anonymous reviewers for their helpful comments and in the research of literature. This paper is part of ASOC's endorsed IPY project "Enhancing the environmental legacy of the IPY". It also forms an output of the British Antarctic Survey's BIOPEARL, LTMS-B and Environment and Information Division LTMS projects, and the SCAR "Evolution and Biodiversity in Antarctica" programme. DGA's time in contributing to this project was funded by the National Science Foundation (OPP-0440463), although the views expressed herein may not be those of NSF.

\section{References}

Adamson, E., Adamson, H. \& Seppelt, R. 1994. Cement dust contamination of Ceratodon purpureus at Casey, East Antarctica: damage and capacity for recovery. Journal of Bryology, 18, 127-137.
Agnew, D.J. 2004. Fishing south - the history and management of South Georgia fisheries. St. Albans: Penna Press, 123 pp.

Agnew, D., Pearce, J., Peatman, T., Pitcher, T.J. \& Pramod, G. 2008. The global extent of illegal fishing. London: MRAG, $32 \mathrm{pp}$.

Ainley, D.G. \& Blight, L.K. 2008. Ecological repercussions of historical fish extraction from the Southern Ocean. Fish \& Fisheries, 10.1111/ j.1467-2979.2008.00293.x.

Ainley, D.G., Ballard, G., Ackley, S., Blight, L.K., Eastman, J.T., Emslie, S.D., Lescroël, A., Olmastroni, S., Townsend, S.E., Tynan, C.T., Wilson, P. \& Woehler, E. 2007. Paradigm lost, or, is top-down forcing no longer significant in the Antarctic marine ecosystem? Antarctic Science, 19, 283-290.

Aislabie, J., Fraser, R., Duncan, S. \& Farrell, R.L. 2001. Effects of oil spills on microbial heterotrophs in Antarctic soils. Polar Biology, 24, 308-313.

Aislabie, J.M., Balks, M.R., Foght, J.M. \& Waterhouse, E.J. 2004. Hydrocarbon spills on Antarctic soils: effects and management. Environmental Science and Technology, 38, 1265-1274.

Alonzo, S.H., Switzer, P.V. \& Mangel, M. 2003. An ecosystem-based approach to management: using individual behavior to predict the indirect effects of Antarctic krill fisheries on penguin foraging. Journal of Applied Ecology, 40, 692-702.

ASOC (Antarctic and Southern Ocean Coalition). 2004. Environmental reports of Fildes Peninsula, 1988-1997: benchmarks for environmental management. Antarctic and Southern Ocean Coalition report, December 2004, $15 \mathrm{pp}$.

ATS (Antarctic Treaty Secretariat). 1994. Recommendation XVIII-1: guidelines for tourism. Final Report of the eighteenth Antarctic Treaty Consultative Meeting, Kyoto, 11-22 April 1994.

ATS (Antarctic Treaty Secretariat). 2008a. Resolution 2 (2008): site guidelines for visitors. Final Report of the XXXI Antarctic Treaty Consultative Meeting, Kiev, 2-13 June 2008.

ATS (Antarctic Treaty Secretariat). 2008b. Final report of XXX Antarctic Treaty Consultative Meeting, New Delhi, 30 April-11 May 2007.

Australia. 2005. Scott Base and McMurdo Station: report of an inspection under Article VII of the Antarctic Treaty and Article 14 of the Protocol on Environmental Protection. June 2005. Department of Foreign Affairs and Trade, Department of the Environment and Heritage, Australia. Working Paper 16 for XXVIII Antarctic Treaty Consultative Meeting, Stockholm, 6-17 June 2005.

Azmi, O.R. \& Seppelt, R.D. 1998. The broad-scale distribution of microfungi in the Windmill Islands region, Antarctica. Polar Biology, 19, 92-100.

BAKER, C.S. \& Clapham, P.J. 2002. Marine mammal exploitation: whales and whaling. In Douglas, I., ed. Encyclopaedia of global environmental change: vol. 3. Causes and consequences of global environmental change. Chichester: John Wiley \& Sons, 446-450.

BAKER, G., Tow, L.A. \& Cowan, D.A. 2003. Detection of non-indigenous micro-organisms in 'pristine' environments, Journal of Microbiological Methods, 53, 157-164.

Ballance, L., Pitman, R.L., Hewitt, R.P., Siniff, D.B., Trivelpiece, W.Z., Clapham, P.J. \& Brownell JR, R.L., 2006. The removal of large whales from the Southern Ocean: evidence for long-term ecosystem effects? In Estes, J.A., Demaster, D.P., Doak, D.F., Williams, T.E. \& Brownell

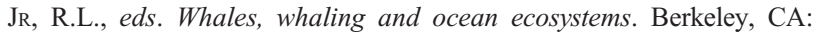
University of California Press, 215-230.

Ballard, G., Ainley, D.G., Ribic, C.A. \& Barton, K.R. 2001. Effect of instrument attachment on foraging trip duration and nesting success of Adélie penguins. Condor, 103, 481-490.

BARGaGli, R. 2005. Antarctic ecosystems: environmental contamination, climate change, and human impact. Berlin: Springer, 395 pp.

Barnes, D.K.A., Hodgson, D.A., Convey, P., Allen, C.S. \& Clarke, A. 2006. Incursion and excursion of Antarctic biota: past, present and future. Global Ecology and Biogeography, 15, 121-142.

Barrera-Oro, E.R. \& Marschoff, E. 2007. Information on the status of fjord Notothenia rossii, Gobionotothem gibberifrons and Notothenia coriiceps 
in the lower South Shetland Islands, derived from 2000-2006 monitoring program at Potter cove. CCAMLR Science, 14, 83-86.

BAS (British Antarctic Survey). 2004. Antarctica, 1: 10000000 scale map. BAS (Misc) 11. Cambridge: British Antarctic Survey.

BastmeiJer, C.J. \& Roura, R. 2004. Regulating Antarctic tourism and the precautionary principle. American Journal of International Law, 98, $763-781$

Bastmeijer, C.J. \& Roura, R. 2007. Environmental impact assessment in Antarctica. In BastmeiJer, C.J. \& Koivurova, T., eds. Theory and practice of transboundary environmental impact assessment. Leiden: Martinus Nijhoff, 175-219.

Bertram, E. 2007. Antarctic ship-borne tourism: an expanding industry. In Snyder, J.M. \& Stonehouse, B., eds. Prospects for polar tourism. Wallingford: CABI International, 149-169.

Bergstrom, D.M. \& Chown, S.L. 1999. Life at the front: history, ecology and change on southern ocean islands. Trends in Ecology and Evolution, 14, 472-476.

Bergstrom, D.M., Convey, P. \& Huiskes, A.H.L. 2006. Trends in Antarctic terrestrial and limnetic ecosystems: Antarctica as a global indicator. Dordrecht: Springer, $365 \mathrm{pp}$.

Beyer, L. \& Bölter, M. 2002. Geoecology of Antarctic ice free coastal landscapes. Berlin: Springer, $463 \mathrm{pp}$.

BLACK, A. 2005. Light induced seabird mortality on vessels operating in the Southern Ocean: incidents and mitigation measures. Antarctic Science, 17, 67-68.

Blanchette, R., Held, B.W., Jurgens, J.A., Aislabie, J., Duncan, S. \& FARRELL, R.L. 2004. Environmental pollutants from the Scott and Shackleton expeditions during the "Heroic Age" of Antarctic exploration. Polar Record, 40, 143-151.

Boenigk, J., Pfandl, K., Garstecki, T., Harms, H., Novarino, G. \& Chatzinotas, A. 2006. Evidence for geographic isolation and signs of endemism within a protistan morphospecies. Applied and Environmental Microbiology, 72, 5159-5164.

Bricher, P.K., LucieER, A. \& Woehler, E.J. 2008. Population trends of Adélie penguin (Pygoscelis adeliae) breeding colonies: a spatial analysis of the effects of snow accumulation and human activities. Polar Biology, 10.1007/s00300-008-0479-z.

BROADY, P.A. 1996. Diversity, distribution and dispersal of Antarctic terrestrial algae. Biodiversity and Conservation, 5, 1307-1335.

BRown, C.R. \& Adams, N.J. 1983. The effect of underwater explosions on rockhopper penguins Eudyptes chrysocome. Cormorant, 11, 68.

Bugoni, L., Neves, T.S., Leite JR, N.O., Carvalho, D., Sales, G., Furness, R.W., Stein, C.E., Peppes, F.V., Giffoni, B.B. \& Monteiro, D.S. 2007. Potential bycatch of seabirds and turtles in hook-and-line fisheries of the Itaipava fleet, Brazil. Fisheries Research, 90, 217-224.

Burger, J. \& Gochfeld, M. 2007. Responses of emperor penguins (Aptenodytes forsteri) to encounters with ecotourists while commuting to and from their breeding colony. Polar Biology, 30, 1303-1313.

Burton, H. \& VAN DEN HofF, J. 2002. Humans and the southern elephant seal Mirounga leonina. Australian Mammalogy, 24, 127-139.

Campbell, I.B., Claridge, G.G.C. \& Balks, M.R. 1998. Short and long-term impacts of human disturbance on snow-free surfaces in Antarctica. Polar Record, 34, 15-24.

Carlini, A.R., Coria, N.R., Santos, M.M., Libertelli, M.M. \& Donini, G. 2007. Breeding success and population trends in Adélie Penguins in areas with low and high levels of human disturbance. Polar Biology, 30, 917-924.

CCAMLR. 1990. Statistical bulletin, Vol. 1 (1970-1979). Hobart: CCAMLR, $61 \mathrm{pp}$.

CCAMLR. 2002. Report of the Twenty-first Meeting of the Scientific Committee. Hobart: CCAMLR, 524 pp, paragraph 5.19.

CCAMLR. 2003. Report of the Twenty-second Meeting of the Scientific Committee. Hobart: CCAMLR, 524 pp.

CCAMLR. 2005. CCAMLR symposium. 5-8 April 2005. Universidad Austral de Chile, Valdivia, Chile. Volume 1: Report of the Chairs, Chile and Australia. Kingston: Australian Antarctic Division, 32 pp.
CCAMLR. 2007. Report of the Twenty-sixth Meeting of the Scientific Committee. Hobart: CCAMLR, 702 pp.

CCAMlR Performance Review Panel. 2008. Report of the CCAMLR performance review panel. Hobart: CCAMLR, $180 \mathrm{pp}$.

Chapman, P.M. \& RidDle, M.J. 2005. Toxic effects of contaminants in polar marine environments. Environmental Science \& Technology, 39, 200A-207A.

Chapman, P.M., McDonald, B.G., Kickham, P.E. \& McKinnon, S. 2006. Global geographic differences in marine metals toxicity. Marine Pollution Bulletin, 52, 1081-1084.

Chen, J. \& Blume, H.-P. 1997. Impact of human activities on the terrestrial ecosystem of Antarctica: a review. Polarforschung, 65, 83-92.

Chown, S.L. \& Convey, P. 2007. Spatial and temporal variability across life's hierarchies in the terrestrial Antarctic. Philosophical Transactions of the Royal Society of London, B362, 2307-2331.

Clarke, A. 2003, Evolution, adaptation and diversity: global ecology in an Antarctic context. In HuISKes, A.H.L, GIesKes, W.W.C., RozemA, J., Schorno, R.M.L., Van Der Vries, S.M. \& Wolff, W.J., eds. Antarctic biology in a global context. Leiden: Backhuys, 3-17.

Clarke, A. \& Harris, C.M. 2003. Polar marine ecosystems: major threats and future change. Environmental Conservation, 30, 1-25.

Clarke, A., Barnes, D.K.A. \& Hodgson, D.A. 2005. How isolated is Antarctica? Trends in Ecology and Evolution, 20, 1-3.

Clarke, J. \& KeRRY, K. 1998. Implanted transponders in penguins: implantation, reliability, and long term effects. Journal of Field Ornithology, 69, 149-159.

Clayton, M.N., Wiencke, C. \& Kiöser, H. 1997. New records and subAntarctic marine benthic macroalgae from Antarctica. Polar Biology, 17, $141-149$.

Cobley, N.D. \& Shears, J.R. 1999. Breeding performance of gentoo penguins (Pygoscelis papua) at a colony exposed to high levels of human disturbance. Polar Biology, 21, 355-360.

COMNAP (Council of Managers of National Antarctic Programs). 1999. An assessment of environmental emergencies arising from activities in Antarctica. Working Paper 16 for XXIII Antarctic Treaty Consultative Meeting, Lima, 24 May-4 June 1999.

Conlan, K.E., Rau, G.H. \& Kvitek, R.G. 2006. delta C-13 and delta N-15 shifts in benthic invertebrates exposed to sewage from McMurdo Station, Antarctica. Marine Pollution Bulletin, 52, 1695-1707.

Conlan, K.E., Kim, S.L., Lenihan, H.S. \& Oliver, J.S. 2004. Benthic changes during 10 years of organic enrichment by McMurdo Station, Antarctica. Marine Pollution Bulletin, 49, 43-60.

Connor, M.A. 2008. Wastewater treatment in Antarctica. Polar Record, 44, $165-171$.

Constable, A.J. 2001. The ecosystem approach to managing fisheries: achieving conservation objectives for predators of fished species. CCAMLR Science, 8, 37-64.

ConstABLE, A.J. 2002. CCAMLR ecosystem monitoring and management: future work. CCAMLR Science, 9, 233-253.

Constable, A.J. 2004. Managing fisheries effects on marine food webs in Antarctica: trade-offs among harvest strategies, monitoring, and assessment in achieving conservation objectives. Bulletin of Marine Science, 74, 583-605.

Convey, P. 1996. The influence of environmental characteristics on the life history attributes of Antarctic terrestrial biota. Biological Reviews, 71, 191-225.

Convey, P. 2006. Antarctic climate change and its influences on terrestrial ecosystems. In Bergstrom, D.B., Convey, P. \& Huiskes, A.H.L., eds. Trends in Antarctic terrestrial and limnetic ecosystems. Antarctica as a global indicator. Dordrecht: Springer, 253-272.

Convey, P. 2007. Antarctic ecosystems. In Levin, S.A., ed. Encyclopedia of biodiversity, 2nd ed. San Diego, CA: Elsevier, 10.1016/B0-12-226865-2/ 00014-6.

Convey, P. 2008. Non-native species in Antarctic terrestrial and freshwater environments: presence, sources, impacts and predictions. In RoGANFinnemore, M., ed. Non-native species in the Antarctic: Proceedings. Christchurch: Gateway Antarctica, 97-130. 
Convey, P. \& Block, W. 1996. Antarctic dipterans: ecology, physiology and distribution. European Journal of Entomology, 93, 1-13.

Convey, P. \& McInnes, S.J. 2005. Exceptional, tardigrade dominated, ecosystems from Ellsworth Land, Antarctica. Ecology, 86, $519-527$.

Convey, P. \& Stevens, M.I. 2007. Antarctic biodiversity. Science, 317, $1877-1878$.

Convey, P., Barnes, D.K.A. \& Morton, A. 2002. Artefact accumulation on Antarctic oceanic island shores. Polar Biology, 25, 612-617.

Convey, P., Greenslade, P. \& Pugh, P.J.A. 2000a. Terrestrial fauna of the South Sandwich Islands. Journal of Natural History, 34, 597-609.

Convey, P., Frenot, F., Gremmen, N. \& Bergstrom, D. 2006. Biological invasions. In Bergstrom, D.B., Convey, P. \& Huiskes, A.H.L., eds. Trends in Antarctic terrestrial and limnetic ecosystems. Antarctica as a global indicator. Dordrecht: Springer, 193-220.

Convey, P., Smith, R.I.L., Peat, H.J. \& Pugh, P.J.A. 2000b. The terrestrial biota of Charcot Island, eastern Bellingshausen Sea, Antarctica an example of extreme isolation. Antarctic Science, 12, 406-413.

Convey, P., Gibson, J., Hillenbrand, C.-D., Hodgson, D.A., Pugh, P.J.A., Smellie, J.L. \& Stevens, M.I. 2008. Antarctic terrestrial life challenging the history of the frozen continent? Biological Reviews, 101111/j.1469-185X.2008.00034.x

CoOney, R. \& Dickson, B. 2005. Biodiversity and the precautionary principle: risk and uncertainty in conservation and sustainable use. London: Earthscan, 314 pp.

Crockett, A.B. \& White, G.J. 2003. Mapping sediment contamination and toxicity in Winter Quarters Bay, McMurdo Station, Antarctica. Environmental Monitoring and Assessment, 85, 257-275.

Croxall, J.P. \& Nicol, S. 2004. Management of Southern Ocean fisheries: global forces and future sustainability. Antarctic Science, 16, 569-584.

Croxall, J.P., Rivera, K. \& Moreno, C.A. 2007. Seabird by-catch mitigation: the southern Ocean (CCAMLR) experience, chapter 8. In Kennelly, S.J., ed. By-catch reduction in the world's fisheries. New York: Springer, 271-281.

Croxall, J.P., Prince, P.A., Rothery, P. \& Wood, A.G. 1998. Population changes in albatross at South Georgia. In Robertson, G. \& Gales, R., eds. The albatross: their biology and conservation. Chipping Norton: Surrey Beatty \& Sons, 69-83.

Crumrine, K.Z. 1992. Surface remediation at McMurdo Station, Antarctica. Proceedings of the fifth symposium on Antarctic logistics and operations. San Carlos de Bariloche, Republica Argentina, 8-10 June, 1992, 41-60.

Daskalov, G.M., Grishin, A.N., Rodionov, S. \& Mihneva, V. 2007. Trophic cascades triggered by overfishing reveal possible mechanisms of ecosystem regime shifts. Proceedings of the National Academy of Sciences, 104, 10518-10523.

DE LEEuw, C. 1994. Tourism in Antarctica and its impact on vegetation. $\mathrm{PhD}$ thesis, Groningen: Arctic Centre, University of Groningen. [Unpublished].

Delille, D. \& Delille, E. 2000. Distribution of enteric bacteria in Antarctic seawater surrounding the Dumont d'Urville permanent station (Adélie Land). Marine Pollution Bulletin, 40, 869-872.

Delille, D., Coulon, F. \& Pelletier, E. 2004. Biostimulation of natural microbial assemblages in oil-amended vegetated and desert subAntarctic soils. Microbial Ecology, 47, 407-415.

Delord, K., Gasco, N., Weimerskirch, H. \& Barbraud, C. 2005. Seabird mortality in the Patagonian toothfish longline fishery around Crozet and Kerguelen islands, 2001-2003. CCAMLR Science, 12, 53-80.

de Poorter, M., Gilbert, N., Storey, B. \& Rogan-Finnemore, M. 2006. Final report of the non-native species in the Antarctic workshop. Christchurch: Gateway Antarctica, 40 pp.

DE VilLiers, M. 2008. Review of recent research into the effects of human disturbance on wildlife in the Antarctic and sub-Antarctic region. In Human disturbance to wildlife in the broader Antarctic region: a review of findings. Appendix 1. Working Paper 12 for XXXI Antarctic Treaty Consultative Meeting, Kiev, Ukraine, 2-13 June 2008. de Villiers, M., Bause, M., Giese, M. \& Fourie, A. 2006. Hardly hardhearted: heart rate responses of incubating northern giant petrels (Macronectes halli) to human disturbance on sub-Antarctic Marion Island. Polar Biology, 29, 717-720.

DeVries, A.L., Ainley, D.G. \& Ballard, G. 2008. Decline of the Antarctic toothfish and its predators in McMurdo sound and the southern Ross Sea, and recommendations for restoration. CCAMLR Document, WG-EMM08/xx. Hobart, TAS: CCAMLR.

Dózsa-Farkas, K. \& Convey, P. 1997. Christensenia, a new enchytraeid genus from Antarctica. Polar Biology, 17, 482-486. [this paper subsequently modified - see Erratum, Polar Biology, 20, 292 (1998)].

Dugger, K.M., Ballard, G. Ainley, D.G. \& Barton, K. 2006. Effects of flipper-bands on apparent survival and foraging behavior of Adélie penguins. The Auk, 123, 858-869.

Duhamel, G., Gasco, P. \& Davaine, P. 2005. Poissons des îles Kerguelen et Crozet. Guide Régional de l'Océan Austral. Paris: Muséum National d'Histoire Naturelle, $419 \mathrm{pp}$.

Edwards, D.D., McFeters, G.A. \& Venkatsean, M.I. 1998. Distribution of Clostridium perfringens and fecal sterols in a benthic coastal marine environment influenced by the sewage outfall from McMurdo Station, Antarctica. Applied and Environmental Microbiology, 64, 2596-2600.

Emslie, S.D. \& Patterson, W.P. 2007. Abrupt recent shift in $\delta 13$ and $\delta 15 \mathrm{~N}$ values in Adélie penguin eggshell in Antarctica. Proceedings of the National Academy of Sciences, 104, 11 666-11 669.

Evans, C.W., Hills, J.M. \& Dickson, J.M.J. 2000. Heavy metal pollution in Antarctica: a molecular ecotoxicological approach to exposure assessment. Journal of Fish Biology, 57, A8-A19.

Filler, D., Snape, I. \& Barnes, D., eds. 2008. Bioremediation of petroleum hydrocarbons in cold regions. Cambridge: Cambridge University Press, $288 \mathrm{pp}$.

FowLER, G.S. 1999. Behavioral and hormonal responses of Magellanic penguins (Spheniscus magellanicus) to tourism and nest site visitation. Biological Conservation, 90, 143-149.

Fraser, W.R. \& Patterson, D.L. 1997. Human disturbance and long-term changes in Adélie penguin populations: a natural experiment at Palmer Station, Antarctic Peninsula. In Battaglia, B., Valencia, J., Walton, D.W.H., eds. Antarctic communities: species, structure and survival. Cambridge: Cambridge University Press, 445-452.

Freckman, D.W. \& Virginia, R.A. 1997, Low-diversity Antarctic soil nematode communities: distribution and response to disturbance. Ecology, 78, 363-369.

Frenot, Y., Chown, S.L., Whinam, J., Selkirk, P., Convey, P., Skotnicki, M. \& Bergstrom, D. 2005. Biological invasions in the Antarctic: extent, impacts and implications. Biological Reviews, 80, 45-72.

Frenot, Y., Convey, P., Lebouvier, M., Chown, S.L., Whinam, J., Selkirk, P.M., Skotnicki, M. \& Bergstrom, D.M. 2008. Antarctic biological invasions: sources, extents, impacts and implications. In RoGANFINNEMORE, M., ed. Non-native species in the Antarctic: proceedings. Christchurch: Gateway Antarctica, 53-96.

Gasparon, M., Ehrler, K., Matschullat, J. \& Melles, M. 2007. Temporal and spatial variability of geochemical backgrounds in the Windmill Islands, East Antarctica: implications for climatic changes and human impacts. Applied Geochemistry, 22, 888-905.

Gaston, K.J., Jones, A.G., Hänel, C. \& Chown, S.L. 2003. Rates of species introduction to a remote oceanic island. Proceedings of the Royal Society of London, B270, 1091-1098.

Gauthier-Clerc, M., Gendner, J.-P., Ribic, C.A., Fraser, W.R., Woehler, E.J., Descamps, S., Gilly, C., Bohec, C.L. \& Maho, Y.L. 2004. Longterm effects of flipper bands on penguins. Proceedings of the Royal Society of London, B271, S423-S426.

George, A.L. 2002. Seasonal factors affecting surfactant biodegradation in Antarctic coastal waters: comparison of a polluted and pristine site. Marine Environmental Research, 53, 403-415.

Giese, M. \& RiddLe, M. 1999. Disturbance of emperor penguin Aptenodytes forsteri chicks by helicopters. Polar Biology, 22, 366-371. 
Goerke, H., Weber, K., Bornemann, H., Ramdohr, S. \& Plotz, J. 2004. Increasing levels and biomagnification of persistent organic pollutants (POPs) in Antarctic biota. Marine Pollution Bulletin, 48, 295-302. Gon, O. \& Heemstra, P.C. 1990. Fishes of the Southern Ocean. Grahamstown: JLB Smith Institute of Ichthyology, $462 \mathrm{pp}$.

Gore, D.B., Revill, A.T. \& Guille, D. 1999. Petroleum hydrocarbons ten years after spillage at a helipad in Bunger Hills, East Antarctica. Antarctic Science, 11, 427-429.

Green, G., Skerratt, J.H., Leeming, R. \& Nichols, P.D. 1992. Hydrocarbon and coprostanol levels in seawater, sea-ice algae and sediments near Davis Station in eastern Antarctica - a regional survey and preliminary-results for a field fuel spill experiment. Marine Pollution Bulletin, 25, 293-302.

Greenslade, P. 1995. Collembola from the Scotia Arc and Antarctic Peninsula including descriptions of two new species and notes on biogeography. Polskie Pismo Entomologiczne, 64, 305-319.

Greenslade, P. 2006. The invertebrates of Macquarie Island. Kingston: Australian Antarctic Division, xvi +326 pp.

Greenslade, P. \& Wise, K.A.J. 1984. Additions to the collembolan fauna of the Antarctic. Transactions of the Royal Society of South Australia, 108, 203-205.

Gregory, M.R. \& Ryan, P.G. 1997. Pelagic plastics and other seaborne persistent synthetic debris: a review of Southern Hemisphere perspectives. In COE, J.M. \& Rogers, D.B., eds. Marine debris: sources, impacts and solutions. New York: Springer, 49-66.

Gremmen, N. \& Smith, V. 2004. The flora of Marion and Prince Edward islands. Diever: Data Analyse Ecologie, CD-ROM.

Gremmen, N.J.M., Smith, V.R. \& van Tongeren, O.F.R. 2003. Impact of trampling on the vegetation of subantarctic Marion Island. Arctic, Antarctic, and Alpine Research, 35, 442-446.

Gröndahl, F., Sidenmark, J. \& Thomsen, A. 2008. Survey of waste water disposal practices at Antarctic research stations. Polar Research, 10.1111/j.1751-8369.2008.00056.x

Hale, R.C., Kim, S.L., Harvey, E., La Guardia, M.J., Mainor, T.M., Bush, E.O. \& JACOBS, E.M. 2008. Antarctic research bases: local sources of Polybrominated Diphenyl Ether (PBDE) flame retardants. Environmental Science and Technology, 42, 1452-1457.

Halpern, B.S., Walbridge, S., Selkoe, K.A., Kappel, C.V., Micheli, F., D’Agrosa, C., Bruno, J.F., Casey, K.S., Ebert, C., Fox, H.E., Fujta, R., Heinemann, D., Lenihan, H.S., Madin, E.M.P., Perry, M.T., Selig, E.R., Spalding, M., Steneck, R. \& Watson, R. 2008. A global map of human impact on marine ecosystems. Science, 319, 948-952.

Hansom, J.D. \& GoRdon, J.E. 1998. Antarctic environments and resources. Harlow: Longman, 402 pp.

HARRIS, C.M. 1991. Environmental management on King George Island, South Shetland Islands, Antarctica. Polar Record, 27, 313-324.

HARRIS, C.M. 2005. Aircraft operations near concentrations of birds in Antarctica: the development of practical guidelines. Biological Conservation, 125, 309-322.

Hee, J.H., Ahn, I.-Y., Lees, K.S., Chung, H. \& Choi, H.-G. 2007. Vegetation of Barton Peninsula in the neighbourhood of King Sejong Station (King George Island, maritime Antarctica). Polar Biology, 30, 903-916.

Hemmings, A.D. 1997. Cumulative impact on Antarctic intrinsic, wilderness and aesthetic values. In DE PoOrTer, M. \& Dalziell, J.C., eds. Environmental impacts in Antarctica: minimisation and management. Proceedings of the IUCN Workshop 18-21 September 1996, Washington DC, 62-64.

Hemmings, A.D. \& Roura, R. 2003. A square peg in a round hole: fitting impact assessment under the Antarctic Environmental Protocol to Antarctic tourism. Impact assessment and project appraisal, 21, 13-24.

Hernandez, J., Prado, V., Torres, D., Waldemstrom, J., Haemig, P.D. \& Olsen, B. 2007. Enteropathogenic Escherichia coli (EPEC) in Antarctic fur seals Arctocephalus gazella. Polar Biology, 30, 1227-1229.

Hofman, R. \& JаtKo, J. 2000. Assessment of the possible cumulative environmental impacts of commercial ship-based tourism in the Antarctic Peninsula Area. Proceedings of a workshop held in La Jolla, June 2000, National Science Foundation, Washington, 94 pp.
Hogg, I.D., Cary, S.C., Convey, P., Newsham, K.K., O’Donnell, T., Adams, B.J., Aislabie, J., Frati, F.F., Stevens, M.I. \& Wall, D.H. 2006. Biotic interactions in Antarctic terrestrial ecosystems: are they a factor? Soil Biology and Biochemistry, 38, 3035-3040.

Holmes, N. 2007. Comparing king, gentoo, and royal penguin responses to pedestrian visitation. Journal of Wildlife Management, 71, 25752582.

Holmes, N.D., Giese, M. \& Kriwoken, L.K. 2008. Linking variation in penguin responses to pedestrian activity for best practise management on subantarctic Macquarie Island. Polarforschung, 77, 7-15

Howington, J.P., McFeters, G.A., Barry, J.P. \& Smith, J.J. 1992. Distribution of McMurdo Station sewage plume. Marine Pollution Bulletin, 25, 324-327.

HugHes, K.A. 2003a. Influence of seasonal environmental variables on the distribution of presumptive fecal coliforms around an Antarctic research station. Applied and Environmental Microbiology, 69, 48844891.

Hughes, K.A. 2003b. Aerial dispersal and survival of sewage-derived faecal coliforms in Antarctica. Atmospheric Environment, 37, 3147-3155.

Hughes, K.A. 2004. Reducing sewage pollution in the Antarctic marine environment using a sewage treatment plant. Marine Pollution Bulletin, 49, 850-853.

HugHes, K.A. 2005. Effect of Antarctic solar radiation on sewage bacteria viability. Water Research, 39, 2237-2244.

Hughes, K.A. 2006. Bird Island path survey. Cambridge: British Antarctic Survey, Internal report, $53 \mathrm{pp}$.

Hughes, K.A. \& BlenkHARn, N. 2003. A simple method to reduce discharge of sewage microorganisms from an Antarctic research station. Marine Pollution Bulletin, 46, 353-357.

Hughes, K.A. \& NobBs, S.J. 2004. Long-term survival of human faecal microorganisms on the Antarctic Peninsula. Antarctic Science, 16, $293-297$.

Hughes, K.A. \& Thompson, A. 2004. Distribution of sewage pollution around a maritime Antarctic research station indicated by faecal coliforms, Clostridium perfringens and faecal sterol markers. Environmental Pollution, 127, 315-321.

Hughes, K., Оtт, S., Bölter, M. \& Convey, P. 2006. Colonisation processes. In Bergstrom, D.B., Convey, P. \& Huiskes, A.H.L., eds. Trends in Antarctic terrestrial and limnetic ecosystems. Antarctica as a global indicator. Dordrecht: Springer, 35-54.

Hughes, K.A., Walsh, S., Convey, P., Richards, S. \& Bergstrom, D.M. 2005. Alien fly populations established at two Antarctic research stations. Polar Biology, 28, 568-570.

Hughes, K.A., Waluda, C.M., Stone, R.E., Ridout, M.S. \& Shears, J.R. 2008. Short-term responses of king penguins Aptenodytes patagonicus to helicopter disturbance at South Georgia. Polar Biology, 10.1007/ s00300-008-0492-2

Huiskes, A.H.L., Bergstrom, D.B. \& Convey, P. 2006. Trends in Antarctic terrestrial and limnetic ecosystems. Antarctica as a global indicator. In Bergstrom, D.B., Convey, P. \& Huiskes, A.H.L., eds. Trends in Antarctic terrestrial and limnetic ecosystems. Antarctica as a global indicator. Dordrecht: Springer, 1-15.

IAATO (International Association for Antarctic Tour Operations). 2007. Report of the International Association of Antarctic Tour Operators 2006-2007. Information Paper 134 for XXX Antarctic Treaty Consultative Meeting, New Delhi, 30 April-11 May 2007.

IAATO (International Association for Antarctic Tour Operations). 2008. IAATO overview of Antarctic tourism 2007-2008 Antarctic season and preliminary estimates for 2008-2009 Antarctic season. Information Paper 85 for XXXI Antarctic Treaty Consultative Meeting. Kiev, 2-13 June 2008.

JACKSON, S. \& WiLSON, R.P. 2002. The potential costs of flipper-bands to penguins. Functional Ecology, 16, 141-148.

JAPAN. 1996. A grass (seed plant) found in Syowa Station area, East Antarctica. Information Paper 66 for XX Antarctic Treaty Consultative Meeting, Utrecht, 29 April-10 May 1996. 
Jones, C.D., Kock, K.-H. \& Balguerías, E. 2000. Changes in bioamass of eight species of finfish around the South Orkney Islands (subarea 48.2) from three bottom trawl surveys. CCAMLR Science, 7, 53-74.

Jouventin, P. \& Weimerskirch, H. 1990. Longterm changes in seabirds and seal population in the Southern Ocean. In KeRRY, K.R. \& HeMPEL, G., eds. Antarctic ecosystems: ecological change and conservation. Berlin: Springer, 208-213.

Jouventin, P., Stahl, J.C., Weimerskirch, H. \& Mougin, J.L. 1984. The seabirds of the French subantarctic islands and Adélie Land: their status and conservation. In Croxall, J.P., Evans, P.G.H. \& Schreiber, R.W., eds. Status and conservation of the world's seabirds. International Council for Bird Preservation Technical Publication No. 2. Cambridge: ICBP, 609-625.

KenNicutT, M.C. 2003. Spatial and temporal scales of human disturbance: McMurdo Station, Antarctica. Final Report. Austin, TX: Geochemical and Environmental Research Group and Department of Geography, College of Geosciences, Texas A\&M University and Marine Science Institute, $184 \mathrm{pp}$.

Kennicutt, M.C., Sweet, S.T., Fraser, W.R., Stochton, W.L. \& Culver, M. 1991. Grounding of the Bahia Paraiso at Arthur Harbor, Antarctica. 1. Distribution and fate of oil spill related hydrocarbons. Environmental Science and Technology, 25, 509-518.

Kerry, K., Riddle, M. \& Clarke, J. 1999. Diseases of Antarctic wildlife. A Report for The Scientific Committee on Antarctic Research (SCAR) and The Council of Managers of National Antarctic Programs (COMNAP), $104 \mathrm{pp}$.

KeYs, H. 1999. Towards additional protection of Antarctic wilderness areas. Information Paper 80 for XXXII Antarctic Treaty Consultative Meeting. Lima, 24 May-4 June 1999.

Kim, S.L., Thurber, A., Hammerstrom, K. \& Conlan, K. 2007. Seastar response to organic enrichment in an oligotrophic polar habitat. Journal of Experimental Marine Biology and Ecology, 346, 66-75.

KING, C.K. \& RiddLE, M.J. 2001. Effects of metal contaminants on the development of the common Antarctic sea urchin Sterechinus neumayeri and comparisons with tropical and temperate echinoids. Marine Ecology Progress Series, 215, 143-154.

Kоск, K.-H. 1992. Antarctic fish and fisheries. Cambridge: Cambridge University Press, $359 \mathrm{pp}$.

Koск, K.-H. 1998. Changes in the fish biomass around Elephant Island (subarea 48.1) from 1976 to 1996. CCAMLR Science, 5, 165-189.

Kock, K.-H., Belchier, M. \& Jones, C.D. 2004. Is the attempt to estimate the biomass of Antarctic fish from a multi-species survey appropriate for all targeted species? Notothenia rossii in the Atlantic Ocean sector revisited. CCAMLR Science, 11, 141-153.

Kock, K.-H., Purves, M.G. \& Duhamel, G. 2006. Interactions between cetacean and fisheries in the Southern Ocean. Polar Biology, 29, $379-388$.

Kock, K.-H., Reid, K., Croxall, J. \& Nicol, S. 2007. Fisheries in the Southern Ocean: an ecosystem approach. Philosophical Transactions of the Royal Society, B362, 2333-2349.

Kohnen, H. \& Lukin, V. 1998. Dismantling of Georg Forster Station and clean-up of the eastern Schirmacher Oasis. In Hall, J., ed. Proceedings of 7th Symposium on Antarctic logistics and operations. Cambridge: British Antarctic Survey, 289-295.

Knox, G.A. 2006. The biology of the Southern Ocean, 2nd ed. Boca Raton, FL: CRC, $640 \mathrm{pp}$.

Kremser, U., Klemm, P. \& Kötz, W.-D. 2005. Estimating the risk of temporary acoustic threshold shift, caused by hydroacoustic devices, in whales in the Southern Ocean. Antarctic Science, 17, 3-10.

KriwoKen, L.K. \& Rootes, D. 2000. Tourism on ice: environmental impact assessment of Antarctic tourism. Impact Assessment and Project Appraisal, 18, 138-150.

Lawley, B., Ripley, S., Bridge, P. \& Convey, P. 2004. Molecular analysis of geographic patterns of eukaryotic diversity in Antarctic soils. Applied and Environmental Microbiology, 70, 5963-5972.
Laws, R.M. 1994. History and present status of southern elephant seal populations. In LeBoeuf, B.J. \& Laws, R.M., eds. Elephant seals: population ecology, behaviour, and physiology. Berkeley, CA: University of California Press, 49-65.

Lee, J.E. \& Chown, S.L. 2007. Mytilus on the move: transport of an invasive bivalve o the Antarctic. Marine Ecology Progress Series, 339, 307-310.

Lenihan, H.S., Kiest, K.A., Conlan, K.E., Slattery, P.N., Konar, B.H. \& Oliver, J.S. 1995. Patterns of survival and behaviour in Antarctic benthic invertebrates exposed to contaminated sediments: field and laboratory bioassay experiments. Journal of Experimental Marine Biology and Ecology, 192, 233-255.

Lewis, P.N., Bergstrom, D.M. \& Whinam, J. 2006. Barging in: a temperate marine community travels to the Subantarctic. Biological Invasions, 8, 787-795.

Lewis, P.N., RiddLE, M.J. \& Smith, S.D.A. 2005. Assisted passage or passive drift: a comparison of alternative transport mechanisms for nonindigenous coastal species into the Southern Ocean. Antarctic Science, 17, 183-191.

Lewis, P.N., Hewitt, C.L., Riddle, M.J. \& McMinn, A. 2003. Marine introductions in the Southern Ocean: an unrecognised hazard to biodiversity. Marine Pollution Bulletin, 46, 213-223.

Lisle, J.T., Smith, J.J., Edwards, D.D. \& McFeters, G.A. 2004. Occurrence of microbial indicators and Clostridium perfringens in wastewater, water column samples, sediments, drinking water, and Weddell Seal feces collected at McMurdo Station, Antarctica. Applied and Environmental Microbiology, 70, 7269-7276.

Lohan, M.C., Statham, P.J. \& Peck, L. 2001. Trace metals in the Antarctic soft-shelled clam Laternula elliptica: implications for metal pollution from Antarctic research stations. Polar Biology, 24, 808-817.

Martin, J., de Neve, L., Fargallo, J.A., Polo, V. \& Soler, M. 2004. Factors affecting the escape behaviour of juvenile chinstrap penguins, Pygoscelis antarctica, in response to human disturbance. Polar Biology, 27, $775-781$.

Martins, C.C., Venkatesan, M.I. \& Montone, R.C. 2002. Sterols and linear alkylbenzenes in marine sediments from Admiralty Bay, King George Island, South Shetland Islands. Antarctic Science, 14, 244-252.

Martins, C.C., Bicego, M.C., Taniguchi, S. \& Montone, R.C. 2004. Aliphatic and polycyclic aromatic hydrocarbons in surface sediments in Admiralty Bay, King George Island, Antarctica. Antarctic Science, 16, $117-122$.

McClintock, J., Ducklow, H. \& Fraser, W. 2008. Ecological responses to climate change on the Antarctic Peninsula. American Scientist, 96, 302.

McDonald, I.R. \& Murrell, J.C. 1997. The methanol dehydrogenase structural gene $\mathrm{mxaF}$ and its use as a functional gene probe for methanotrophs and methylotrophs. Applied and Environmental Microbiology, 63, 3218-3224.

McIntyre, C.P., Harvey, P.M., Ferguson, S., Wressnig, A.M., Snape, I. \& GEORGE, S.C. 2007. Determining the extent of weathering of spilled fuel in contaminated soil using the diastereomers of pristane and phytane. Organic Geochemistry, 38, 2131-2134.

Micol, T. \& Jouventin, P. 2001. Long-term population trends in seven Antarctic seabirds at Pointe Géologie (Terre Adélie): human impact compared with environmental change. Polar Biology, 24, 175-185.

Moreno, C.A. 1995. By-catch of juvenile fishes in the Antarctic krill fishery. UBC Fisheries Centre Research Reports, 3, 26-34.

Morris, C.E., George, J., Tate, P.M. \& Cathers, B. 2000. Impacts of wastewater discharge to the Antarctic marine environment. In Hughson, T. \& Ruckstuhl, C., eds. Proceedings of the Sixth International Symposium on Cold Region Development, Hobart, 155158.

Muller-Schwarze, D. 1984. Possible human impact on penguin populations in the Antarctic Peninsula area. Antarctic Journal of the United States, 19, $158-159$.

Myers, R.A. \& Worm, B. 2003. Rapid worldwide depletion of predatory fish communities. Nature, 423, 280-283. 
NaveEn, R. 2003. Compendium of Antarctic Peninsula Visitor Sites, 2nd ed. A Report to the United States Environmental Protection Agency. US Environmental Protection Agency.

NAVEEN, R. 2004. Indicators of cumulative impacts on bird and plant populations: approaches taken by the Antarctic Site Inventory. In Practical Biological Indicators of Human Impacts in Antarctica. SCAR/ NSF/COMNAP Workshop, Bryan/College Station, TX, 16-18 March 2005, 8 pp.

Negri, A., Burns, K., Boyle, S., Brinkman, D. \& Webster, N. 2006. Contamination in sediments, bivalves and sponges of McMurdo Sound, Antarctica. Environmental Pollution, 143, 456-467.

Negri, A.P., Hales, L.T., Battershill, C., Wolff, C. \& Webster, N.S. 2004. TBT contamination identified in Antarctic marine sediments. Marine Pollution Bulletin, 48, 1142-1144.

Nel, D.C., Ryan, P.G. \& Watkins, B.P. 2002. Seabird mortality in the Patagonian toothfish longline fishery around the Prince Edward Islands, 1996-2000. Antarctic Science, 14, 151-161.

Nicol, S. \& Endo, Y. 1997. Krill fisheries of the world. Rome: FAO Fisheries Technical Paper 367, 100 pp.

Nicol, S. \& Foster, J. 2003. Recent trends in the fishery for Antarctic krill. Aquatic Living Resources, 16, 42-45.

Nicol, S., Croxall, J., Trathan, P., Gale, N. \& Murphy, E. 2007. Paradigm misplaced? Antarctic marine ecosystems are affected by climate change as well as biological processes and harvesting. Antarctic Science, 19, 291-295.

Northcott, K.A., Snape, I., Scales, P.J. \& Stevens, G.W. 2005. Dewatering behaviour of water treatment sludges associated with contaminated site remediation in Antarctica. Chemical Engineering Science, 60, 68356843.

NoRWAy. 2001. Report of the Norwegian Antarctic Inspection under Article VII of the Antarctic Treaty and Article 14 of the Protocol on Environmental Protection to the Antarctic Treaty, January 2001. Working Paper 25 for XXIV Antarctic Treaty Consultative Meeting, St Petersburg, 9-20 July 2001.

National Science Foundation/COMnAP/SCAR. 2005. Practical biological indicators of human impacts in Antarctica. Bryan, College Station, TX: Workshop Report, 16-18 March 2005. Vols 1 (24 pp) and $2(15 \mathrm{pp})$

O’Brien, J.S., Todd, J.J. \& KriwoKen, L.K. 2004. Incineration of waste at Casey Station, Australian Antarctic Territory. Polar Record, 40, $221-234$.

Ohtani, S., Suvama, K. \& Kanda, H. 2000. Environmental monitoring by means of soil algae and microorganisms in the vicinity of Syowa Station. Nankyoku Shiryo (Antarctic Record), 44, 265-276.

Olech, M. 1996. Human impact on terrestrial ecosystems in West Antarctica. NIPR Symposium on Polar Biology, Proceedings, No. 9, 299-306.

Osterblöm, H., Casini, M., Olsson, O. \& Bignert, A. 2006. Fish, seabirds and trophic cascades in the Baltic Sea. Marine Ecology Progress Series, 323, 233-238.

Osterblöm, H., Hansson, S., Larsson, U., HJerne, O., WulfF, F., Elmgren, R. \& FolKe, C. 2007. Human-induced trophic cascades and ecological regime shifts in the Baltic Sea. Ecosystems, 10, 877-889.

OtLey, Н. 2005. Nature-based tourism: experiences at the Volunteer Point penguin colony in the Falkland Islands. Marine Ornithology, 33, $181-187$

Pauly, D. \& Maclean, J. 2003. In a perfect ocean: the state of fisheries and ecosystems in the North Atlantic Ocean. Washington, DC: Island Press, $175 \mathrm{pp}$.

Pauly, D. \& Palomares, M.L. 2005. Fishing down marine food webs: it is far more pervasive than we thought. Bulletin of Marine Science, 76, 197-211.

Peat, H.J., Clarke, A. \& Convey, P. 2007. Diversity and biogeography of the Antarctic flora. Journal of Biogeography, 34, 132-146.

Peter, H.-U., Buesser, C., Mustafa, O. \& Pfeiffer, S. 2008. Risk assessment for the Fildes Peninsula and Ardley Island, and development of management plans for their designation as Specially
Protected or Specially Managed Areas. Dessau: German Environmental Agency, http://www.umweltdaten.de/publikationen/fpdf-1/3478.pdf

PFEIFFER, S. 2005. Effects of human activities on southern giant petrels and skuas in the Antarctic. PhD thesis, Ecology Institute, University of Jena. Available at: www.db-thueringen.de/servlets/derivateservlet/derivate6345/Pfeiffer.pdf

Pfeiffer, S. \& Peter, H.-U. 2003. Umsetzung des UmweltschutzprotokollAusführungsgesetzes (AUG), Teilvorhaben 3: Bestandsaufnahme und Managementpläne für zwei touristisch genutzte Gebiete der Antarktis. Berlin: Umweltbundesamt, $247 \mathrm{pp}$.

Pfeiffer, S. \& Peter, H.-U. 2004. Ecological studies toward the management of an Antarctic tourist landing site (Penguin Island, South Shetland Islands. Polar Record, 40, 345-353.

Pfeiffer, S., Buesser, C., Mustafa, O. \& Peter, H.-U. 2006. Tourism growth and proposed management solutions in the Fildes Peninsula Region (King George Island, Antarctica). Tourism in Marine Environments, 4, 151-165.

Phillips, R.A., Xavier, J. \& Croxall, J.P. 2003. Effects of satellite transmitters on albatrosses and petrels. Auk, 120, 1082-1090.

PinesChI, L. 2001. The duty of prior environmental impact assessment of Antarctic activities under the Madrid Protocol and its implementation in the Italian legal system. In Caroli, S., Cescon, P. \& Walton, D.W.H., eds. Environmental contamination in Antarctica: a challenge to analytical chemistry. Amsterdam: Elsevier Science, 363-380.

Poland, J.S., Riddle, M.J. \& Zeeb, B.A. 2003. Contaminants in the Arctic and the Antarctic: a comparison of sources, impacts, and remediation options. Polar Record, 39, 369-383.

Poncet, S., Robertson, G., Phillips, R.A., Lawton, K., Phalan, B., Trathan, P.N. \& Croxall, J.P. 2006. Status and distribution of wandering, black browed and grey-headed albatrosses breeding at South Georgia. Polar Biology, 29, 772-781.

Rayner, J.L., Snape, I., Walworth, J.L., Harvey, P.M. \& Ferguson, S.H. 2007. Petroleum-hydrocarbon contamination and remediation by microbioventing at sub-Antarctic Macquarie Island. Cold Regions Science and Technology, 48, 139-153.

Revill, A.T., Snape, I., Lucieer, A. \& Guille, D. 2007. Constraints on transport and weathering of petroleum contamination at Casey Station, Antarctica. Cold Regions Science and Technology, 48, 154-167.

Ropert-Coudert, Y., Wilson, R.P., Yoda, K. \& Kato, A. 2007. Assessing performance constraints in penguins with externally-attached devices. Marine Ecology Progress Series, 333, 281-289.

Rounsevell, D. \& Binns, D. 1991. Mass deaths of king penguins (Aptenodytes patagonica) at Lusitania Bay, Macquarie Island. Aurora, 10, 8-10.

Rounsevel, D.E. \& Copson, G.R. 1982. Growth rate and recovery of a king penguin, Aptenodytes patagonicus, population after exploitation. Australian Wildlife Research, 9, 519-25.

ROURA, R. 2004. Monitoring and remediation of hydrocarbon contamination at the former site of Greenpeace's World Park Base, Cape Evans, Ross Island, Antarctica. Polar Record, 40, 51-67.

Salwicka, K. \& Stonehouse, B. 2000. Visual monitoring of heartbeat and respiration in Antarctic seals. Polish Polar Research, 21, 189-197.

Santos, I.R., Silva, E.V., Schaefer, C.E.G.R., Alburquerque, M.R. \& CAmpos, L.S. 2005. Heavy metal contamination in coastal sediments and soils near the Brazilian Antarctic Station, King George Island. Marine Pollution Bulletin, 50, 185-194.

SCAR (Scientific Committee on Antarctic Research). 2006a. SCAR report on marine acoustics on the Southern Ocean. Working Paper 41 for XXIX Antarctic Treaty Consultative Meeting, Edinburgh, 12-23 June 2006, 17 pp.

SCAR (Scientific Committee on Antarctic Research). 2006b. Proposal to delist fur seals as specially protected species. Working Paper 39 for XXIX Antarctic Treaty Consultative Meeting, Edinburgh, 12-23 June 2006, $13 \mathrm{pp}$.

SCOTt, J.J. \& KirkPatrick, J.B. 1994. Effects of human trampling on the subAntarctic vegetation of Macquarie Island. Polar Record, 30, 207-220. 
Schafer, A.N., Snape, I. \& Siciliano, S.D. 2007. Soil biogeochemical toxicity endpoints for sub-Antarctic islands contaminated with petroleum hydrocarbons. Environmental Toxicology and Chemistry, 26, 890-897.

Seco-Pon, J.P., Gandin, P.A. \& Favero, M. 2007. Effect of longline configuration on seabird mortality in the Argentine semi-pelagic kingklip (Genypterus blacodes) fishery. Fisheries Research, 85, 101-105.

Sheppard, D.S., Claridge, G.G.C. \& Campbell, I.B. 2000. Metal contamination of soils at Scott Base, Antarctica. Applied Geochemistry, 15, 513-530.

SJoling, S. \& Cowan, D.A. 2000. Detecting human bacterial contamination in Antarctic soils. Polar Biology, 23, 644-650.

Sladen, W.L. \& Leresche, R.E. 1970. New and developing techniques in Antarctic ornithology. Antarctic Ecology, 1, 585-596.

SмiтH, R.I.L. 1996. Introduced plants in Antarctica: potential impacts and conservation issues. Biological Conservation, 76, 135-146.

Sмiтн, R.I.L. 2003. The enigma of Colobanthus quitensis and Deschampsia antarctica in Antarctica. In Huiskes, A.H.L., Gieskes, W.W.C., Rozema, J., Schorno, R.M.L., van der Vies, S.M., WolfF, W.J., eds. Antarctic biology in a global context. Leiden: Backhuys Publishers, 234-239.

Sмiтн, R.I.L. 2005. The bryophyte flora of geothermal habitats on Deception Island, Antarctica. Journal of Hattori Botanical Laboratory, 97, $233-248$.

Snape, I., Morris, C.E. \& Cole, C.M. 2001a. The use of permeable reactive barriers to control contaminant dispersal during site remediation in Antarctica. Cold Regions Science and Technology, 32, 157-174.

Snape, I., Ferguson, S.H., Harvey, P.M. \& Riddle, M.J. 2006. Investigation of evaporation and biodegradation of fuel spills in Antarctica: II - extent of natural attenuation at Casey Station. Chemosphere, 63, 89-98.

Snape, I., Gore, D.B., Cole, C.M. \& Riddle, M.J. 2002. Contaminant dispersal and mitigation at Casey Station: an example of how applied geoscience research can reduce environmental risks in Antarctica. Royal Society of New Zealand Bulletin, 35, 641-648.

Snape, I., Harvey, P.M., Ferguson, S.H., Rayner, J.L. \& Revill, A.T. 2005. Investigation of evaporation and biodegradation of fuel spills in Antarctica: I - a chemical approach using GC-FID. Chemosphere, 61, $1485-1494$.

Snape, I., Stark, J.S., Cole, C.M., Gore, D.G., Duquesne, S. \& Riddle, M.J. 2001b. Management and remediation of contaminated sites at Casey Station, Antarctica. Polar Record, 37, 199-214.

Snape, I., Acomb, L., Barnes, D.I., Bainbridge, S., Eno, R., Filler, M., Plato, N., Pol, J.S., Raymond, T.C., Rayner, J.L., Riddle, M.J., Rike, A.G., Rutter, A., Schafer, A.L., Siciliano, S.D. \& Walworth, J.L. 2008. Contamination, regulation and remediation: an introduction to bioremediation of petroleum hydrocarbons in cold regions. In Filler, D., SNAPE, I. \& BARnes, D., eds. Bioremediation of petroleum hydrocarbons in cold regions, Cambridge: Cambridge University Press, 1-37.

Southwell, C. 2005. Response behaviour of seals and penguins to helicopter surveys over the pack ice off East Antarctica. Antarctic Science, 17, $328-334$.

Stark, J.S., Riddle, M.J. \& Simpson, R.D. 2003a. Human impacts in softsediment assemblages at Casey Station, East Antarctica: spatial variation, taxonomic resolution and data transformation. Austral Ecology, 28, 287-304.

Stark, J.S., Snape, I. \& Riddle, M.J. 2003c. The effects of petroleum hydrocarbon and heavy metal contamination of marine sediments on recruitment of Antarctic soft-sediment assemblages: a field experimental investigation. Journal of Experimental Marine Biology and Ecology, 283, $21-50$.

Stark, J.S., Snape, I. \& Riddle, M.J. 2006. Abandoned Antarctic waste disposal sites: monitoring remediation outcomes and limitations at Casey Station. Ecological Management and Restoration, 7, 21-31.

Stark, J.S., Riddle, M.J., Snape, I. \& Scouller, R.C. 2003b. Human impacts in Antarctic marine soft-sediment assemblages: correlations between multivariate biological patterns and environmental variables at Casey Station. Estuarine Coastal and Shelf Science, 56, 717-734.
Stark, J.S., Snape, I., Riddle, M.J. \& Stark, S.C. 2005. Constraints on spatial variability in soft-sediment communities affected by contamination from an Antarctic waste disposal site. Marine Pollution Bulletin, 50, 276-290.

Summerson, R. \& Riddle, M.J. 2000. Assessing wilderness and aesthetic values in Antarctica. In Davison, W., Howard-Williams, C. \& Broady, P., eds. Antarctic ecosystems: models for wider ecological understanding. Christchurch: Caxton Press, 303-307.

Tavares, M. \& de Melo, G.A.S. 2004. Discovery of the first known benthic invasive species in the Southern Ocean: the North Atlantic spider crab Hyas araneus found in the Antarctic Peninsula. Antarctic Science, 16, $129-131$.

Tejedo, P., Austel, A., Benayas, J., Rico, E., Convey, P. \& Quesada, A. In press. Human impact on soils in an Antarctic Specially Protected Areas: tools to evaluate SCAR recommendations. Antarctic Science, 21.

Thatje, S., Anger, K., Calcagno, J.A., Lovrich, G.A., Portner, H.O. \& ARnTZ, W.E. 2005. Challenging the cold: crabs reconquer the Antarctic. Ecology, 86, 619-625.

Thompson, B.A.W., Goldsworthy, P.M., Riddle, M.J., Snape, I. \& Stark, J.S. 2007. Contamination effects by a 'conventional' and a 'biodegradable' lubricant oil on infaunal recruitment to Antarctic sediments: a field experiment. Journal of Experimental Marine Biology and Ecology, 340, 213-226.

THоR, G. 1997. Establishment of permanent plots with lichens and mosses for monitoring local human impact on environment in Heimefrontfjella and Vestfjella, Dronning Maud Land, Antarctica. Nankyoku Shiryo (Antarctic Record), 41, 652-672.

Townsend, A. \& SNAPE, I. 2008. Multiple Pb sources in marine sediments near the Australian Antarctic Station, Casey. Science of the Total Environment, 389, 466-474.

Townsend, A.T. \& SNAPE, I. 2002. The use of $\mathrm{Pb}$ isotope ratios determined by magnetic sector ICP-MS for tracing $\mathrm{Pb}$ pollution in marine sediments near Casey Station, East Antarctica. Journal of Analytical Atomic Spectrometry, 17, 922-928.

Trathan, P.N., Forcada, J., Atkinson, R., Downie, R.H. \& Shears, J. In press. Population assessments of gentoo penguins (Pygoscelis papua) breeding at an important Antarctic tourist site, Goudier Island, Port Lockroy, Palmer Archipelago, Antarctica. Biological Conservation.

Turner, J., Colwell, S.R., Marshall, G.J., Lachlan-Cope, T.A., Carleton, A.M., Jones, P.D., Lagun, V., Reid, P.A. \& Iagovkina, S. 2005. Antarctic climate change during the last 50 years. International Journal of Climatology, 25, 279-294.

United Kingdom Australia \& Peru. 2005. Antarctic Treaty Inspections 2005. Report of Antarctic Treaty Inspections undertaken jointly by the UK, Australia and Peru in accordance with Article VII of the Antarctic Treaty and Article 14 of the Environmental Protocol. Working Paper 32 for XXVIII Antarctic Treaty Consultative Meeting, Stockholm, 6-17 June 2005.

United States. 2001. Team report of the Inspection conducted in accordance with Article VII of the Antarctic treaty and Article XIV of the Protocol under the auspices of the United States Department of State. February 2-16, 2001. Information Paper 17 for XXIV Antarctic Treaty Consultative Meeting, St Petersburg, 9-20 July 2001.

Upton, M., Pennington, T.H. \& Haston, W. 1997. Detecting commensals in the area around an Antarctic research station. Antarctic Science, 9, $156-161$.

Van Ngan, P., Gomes, V., Passos, M.J.A.C.R., Ussami, K.A., Campos, D.Y.F. \& RoснA, A.J.D. 2007. Biomonitoring of the genotoxic potential (micronucleus and erythrocyte nuclear abnormalities assay) of the Admiralty Bay water surrounding the Brazilian Antarctic Research Station "Comandante Ferraz," King George Island. Polar Biology, 30, 209-217.

van Polanen Petel, T.D., Giese, M.A., Wotherspoon, S. \& Hindell, M.A. 2007. The behavioural response of lactating Weddell seals (Leptonychotes weddellii) to over-snow vehicles: a case study. Canadian Journal of Zoology, 85, 488-496. 
van Polanen Petel, T.D., Terhune, J.N., Hindell, M.A. \& Giese, M.A. 2006. An assessment of the audibility of sound from human transport by breeding Weddell seals (Leptonychotes weddellii). Wildlife Research, 33, 275-291.

Walworth, J., Reynolds, C.M., Rutter, A. \& Snape, I. 2008. Landfarming. In Filler, D., Snape, I. \& Barnes, D., eds. Bioremediation of petroleum hydrocarbons in cold regions. Cambridge: Cambridge University Press, $170-189$.

Weber, K. \& Goerke, H. 2003. Persistent organic pollutants (POPs) in Antarctic fish: levels, patterns, changes. Chemosphere, 53, 667-678.

Weimerskirch, H., Shaffer, S.A., Mabille, G., Martin, J., Boutard, O. \& RouAnet, J.L. 2002. Heart rate and energy expenditure of incubating wandering albatrosses: basal levels, natural variation, and the effects of human disturbance. Journal of Experimental Biology, 205, 475-483.

Wheeler, M., de Villiers, M.S. \& Majiedt, P.A. 2008. The effect of frequency and nature of pedestrian approaches on the behaviour of wandering albatrosses at sub-Antarctic Marion Island. Polar Biology, 10.1007/s00300-008-0520-2.

Whinam, J., Chilcott, N. \& Bergstrom, D.M. 2004. Subantarctic hitchhikers: expeditioners as vectors for the introduction of alien organisms. Biological Conservation, 121, 207-219.
Willock, A. \& Lack, M. 2006. Follow the leader: learning from experience and best practice in regional fisheries management organizations. Gland: WWF International and TRAFFIC International, $57 \mathrm{pp}$.

Wilson, R.P., Culik, B. \& Adelung, D. 1991. People in Antarctica - how much do Adélie penguins Pygoscelis adeliae care? Polar Biology, 11, $363-370$

Wilson, R.P., Coria, N.R., Spairani, H.J., Adelung, D. \& Culik, B. 1989. Human-induced behaviour in Adélie penguins Pygoscelis adeliae. Polar Biology, 10, 77-80.

Woehler, E.J., Riddle, M.J. \& Ribic, C.A. 2003. Long-term population trends in southern giant petrels in East Antarctica. In Huiskes, A.H.L., Gieskes, W.W.C., Rozema, J., Schorno, R.M.L., van der Vies, S.M. \& Wolff, W.J., eds. Antarctic biology in a global context. Leiden: Backhuys Publishers, 290-295.

Worm, B., Barbier, E.B., Beaumont, N., Duffy, J.E., Folke, C., Halpern, B.S., Jackson, J.B.C., Lotze, H.K., Micheli, F., Palumbi, S.R., Sala, E., Selkoe, K.A., Stachowicz, J.J. \& Watson, R. 2006. Impacts of biodiversity loss on ocean ecosystem services. Science, 314, 787-790.

Yergeau, E., Bokhorst, S., Huiskes, A.H.L., Boschker, H.T.S., Aerts, R. \& KowalchuK, G.A. 2007. Size and structure of bacterial, fungal and nematode communities along an Antarctic environmental gradient. FEMS Microbiology Ecology, 59, 436-451. 